\title{
Flow regime maps for smooth horizontal tubes at a constant heat flux
}

\author{
M. Everts and J. P. Meyer*
}

*Author for correspondence

Department of Mechanical and Aeronautical Engineering, University of Pretoria, Pretoria, 0002,

South Africa, E-mail: josua.meyer@up.ac.za

\section{Highlights}

- Two flow regime maps for fully developed flow.

- Four flow regime maps for developing and fully developed flow.

- Forced convection results in the transitional flow regime.

\begin{abstract}
The existing constant heat flux boundary condition flow regime maps are accurate for high Prandtl number fluids, however, they are inaccurate at lower Prandtl numbers and tube diameters and specifically for water as the working fluid. The purpose of this paper was to develop a flow regime map that can be used for both high and low Prandtl number fluids for a wide range of tube diameters. Furthermore, not only to develop a map for fully developed flow, but also for developing flow. An experimental set-up was designed, built and validated against results from literature. Two smooth circular test sections with inner diameters of $4 \mathrm{~mm}$ and $11.5 \mathrm{~mm}$, respectively, and lengths of $5.5 \mathrm{~m}$ and $9.5 \mathrm{~m}$, respectively, were used. Heat transfer measurements were taken at a range of Reynolds numbers from laminar to turbulent. Water was used as the test fluid and the Prandtl number was limited between 3 and 7. Experimental results from literature complemented the test matrix used for this study, especially with high Prandtl number data. Six flow regime maps were developed for a constant heat flux boundary condition and a square-edged inlet, and these flow regime maps are original for four reasons. Firstly, it contains contour lines that show the Nusselt number enhancements due to free convection effects. Secondly, it is valid for a wide range of tube diameters and Prandtl numbers. Thirdly, the flow regime maps were developed as a function of temperature difference (Grashof number) and heat flux (modified Grashof number). Finally, four of the six flow regime maps are not only valid for fully developed flow, but also developing flow.
\end{abstract}

Keywords: Flow regime map; mixed convection; developing flow; fully developed flow; heat transfer; constant heat flux; horizontal tubes 


\section{Graphical abstract}

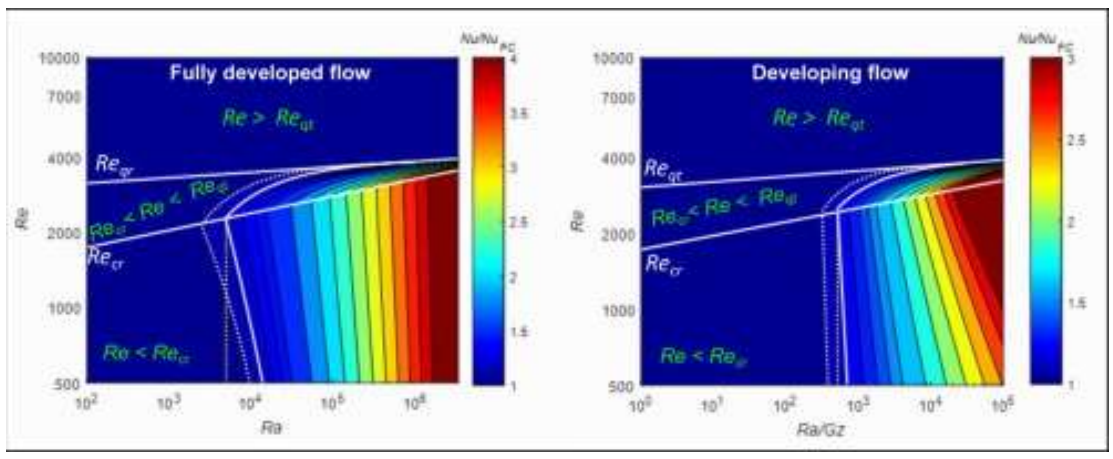

\section{Nomenclature}

A $\quad$ Area

$C_{p} \quad$ Constant-pressure specific heat

$D \quad$ Inner diameter

$D_{o} \quad$ Outer diameter

$E B \quad$ Energy balance

FC/MC Forced/mixed convection boundary

$g \quad$ Gravitational acceleration

Gr Grashof number

$G r^{*} \quad$ Modified Grashof number

$G z \quad$ Graetz number

$h \quad$ Heat transfer coefficient

I Current

$j \quad$ Colburn $j$-factor

$k \quad$ Thermal conductivity

$L \quad$ Length

$L t \quad$ Thermal entrance length

$M \quad$ Measurement or calculated value

$\dot{m} \quad$ Mass flow rate

$n \quad$ Number of thermocouples at station/ number of data points

$\mathrm{Nu} \quad$ Nusselt number

$\mathrm{Pr} \quad$ Prandtl number

$\dot{Q}_{e} \quad$ Electric input rate

$\dot{Q}_{w} \quad$ Water heat transfer rate

$\dot{q} \quad$ Heat flux

$R_{\text {tube }} \quad$ Thermal resistance

$R a \quad$ Rayleigh number

$R a^{*} \quad$ Modified Rayleigh number

Re Reynolds number

$R e_{c r} \quad$ Start of transitional flow regime

$R e_{q t} \quad$ End of transitional flow regime

$R i \quad$ Richardson number

$R i$ Modified Richardson number

$T \quad$ Temperature

$\begin{array}{ll}V & \text { Voltage } \\ x & \text { Distance from inlet } \\ z^{*} & \pi /(4 G z) \text { as in Eq. (39) }\end{array}$

Greek letters

$\beta \quad$ Thermal expansion coefficient

$\varepsilon \quad$ Surface roughness

$\mu \quad$ Dynamic viscosity

$v \quad$ Kinematic viscosity

$\rho \quad$ Density

Superscripts

- Average

Subscripts

$b \quad$ Bottom/bulk

c Cross-section

cor Correlation

exp Experimental

$F C$ Forced convection

$i \quad$ Inlet

$m$ Mean

$o \quad$ Outer/outlet

$s \quad$ Surface

SL Nusselt number obtained using the correlation of Shah and London [1]

$t \quad$ Top

Abbreviations (also used as italic subscripts)

FD Fully Developed region

MCD Mixed Convection

Developing region 


\section{Introduction}

A flow regime map is a valuable tool that can be used to determine whether free convection effects can be neglected (forced convection dominates) or whether it is significant (mixed convection dominates). This needs to be taken into consideration for the selection of appropriate equations, especially for laminar heat transfer cases. Metais and Eckert [2] developed two flow regime maps for a constant surface temperature boundary condition, one for vertical flow and another for horizontal flow. The boundary between forced and mixed convection was arbitrarily defined as the location where the difference between the mixed and forced convection heat transfer coefficients did not exceed 10\%. Ghajar and Tam [3] found that the flow regime map of Metais and Eckert [2] accurately predicted their turbulent forced convection experimental data, but the laminar and transition data were not predicted correctly. This was due to the constant heat flux boundary condition which was used, while the flow regime map was developed for a constant surface temperature. In the laminar and transitional flow regimes, the boundary condition has a significant influence on the heat transfer characteristics, while turbulent flow is insensitive to different boundary conditions. Furthermore, the influence of free convection effects is also stronger with a constant heat flux boundary condition than with a constant surface temperature boundary condition [3].

A flow regime map for horizontal tubes with a constant heat flux boundary condition was therefore developed by Ghajar and Tam [3]. The boundary between forced and mixed convection was obtained using the ratio of the local peripheral heat transfer coefficients at the top and bottom of the tube $\left(h_{t} / h_{b}\right)$. When the ratio of $h_{t} / h_{b}$ was greater than or equal to 0.8 , the flow was assumed to be dominated by forced convection, while mixed convection conditions were assumed when $h_{t} / h_{b}$ was less than 0.8. As far as we could determine, this was the first flow regime map for horizontal tubes with a constant heat flux boundary condition, and it also accounted for the effects of different inlet geometries (re-entrant, square-edged and bellmouth).

Tam et al. [4] improved this flow regime map, by making use of the multi-class support vector machines (SVM) method. Three flow regime maps (re-entrant, square-edged and bellmouth inlets) were developed and the five flow regimes (forced turbulent, forced transition, mixed transition, forced laminar and mixed laminar) were identified using the Rayleigh and Reynolds numbers. Tam et al. [5] then developed a unified SVM-based flow regime map, which can be used for the re-entrant, square-edged and bellmouth inlets. The overall accuracy of this flow regime map was also better than the three individual SVMbased flow regime maps. 
However, as the unified flow regime map of Tam et al. [5] was developed using the experimental data of Ghajar and Tam [6], it is primarily for Rayleigh numbers in the order of $10^{6}$, which is high. The laminar heat transfer experiments were conducted using ethylene glycol, therefore the mixed convection boundary in the laminar flow regime, was developed using experimental data with Prandtl numbers between 23 and 140, which is significantly larger than for water $(\operatorname{Pr} \approx 7)$. Furthermore, the test section had a relatively large inner diameter of $15.8 \mathrm{~mm}$, which led to increased Grashof numbers, since the Grashof number is proportional to $D^{3}$. This is of significant importance since the Rayleigh number, which was used on the $x$-axis of their flow regime map, is a product of the Grashof number, which was large due to the large tube diameter, and Prandtl number, which was high since ethylene glycol was used.

It is shown in this paper that although this flow regime map of Tam et al. [5] may be very accurate for high Prandtl number fluids, it became inaccurate once the Prandtl number and tube diameter was decreased, for example when water was used in small diameter tubes. The result is that the flow is predicted to be in the forced convection regions, while free convection effects are significant and the flow is actually dominated by mixed convection. The purpose of this paper was thus to evaluate the existing flow regime maps using the experimental data from this study, as well as to develop new flow regime maps that can be used for both high and low Prandtl number fluids, a wide range of tube diameters, and not only for fully developed flow, but also developing flow. This paper forms part of a bigger study and is complimentary to the papers published by Meyer and Everts [7] and Everts and Meyer [8,9]. Meyer and Everts [7] investigated mixed convection laminar flow, as well as the effect of free convection on the laminar-turbulent transition along the tube length. Everts and Meyer [8] investigated the heat transfer characteristics of developing and fully developed flow in the transitional flow regime, while the relationship between heat transfer and pressure drop in all flow regimes was investigated and quantified in Everts and Meyer [9]. The results of these papers were used to develop the flow regime maps, for not only fully developed flow but also developing flow, presented in this paper.

\section{Experimental set-up}

The details of the experimental set-up and test sections were discussed in detail in Meyer and Everts [7] and Everts [10] and will only be briefly discussed in this paper. The layout of the experimental set-up is shown in Fig. 1. The experimental set-up consisted of a closed- 
loop system, which circulated water from a storage tank, through the test section and back to the storage tank, using two electronically controlled magnetic gear pumps.

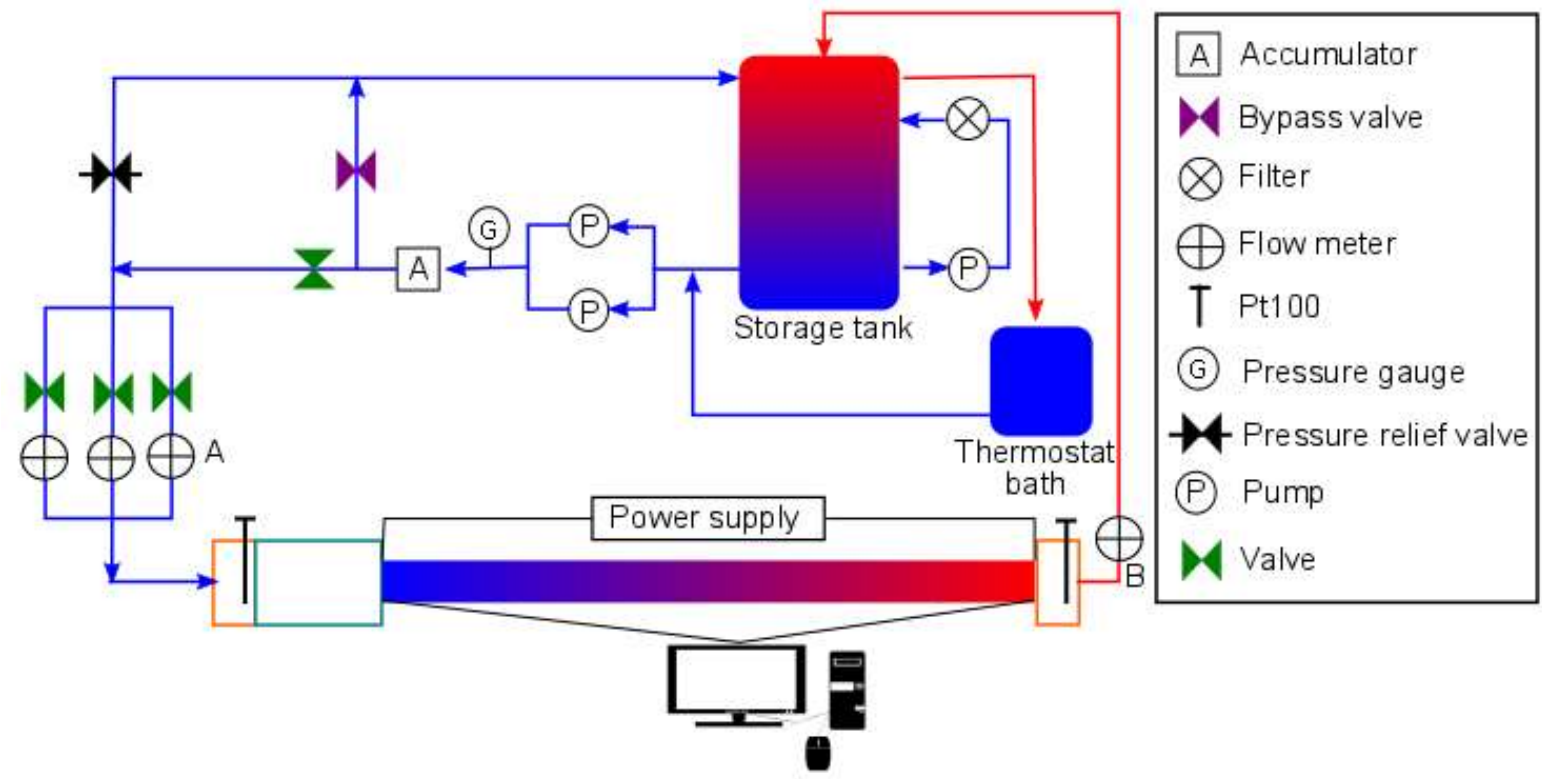

Fig. 1: Schematic representation of experimental set-up used to conduct heat transfer and pressure drop measurements. Water was circulated from the storage tank through the test section and back using two pumps.

As the mass flow rates varied over a wide range, Coriolis mass flow meters with different flow rate capacities were installed in parallel. The mass flow meter that would produce the most accurate mass flow rate measurements was selected during the experiments. Downstream of the mass flow meters, the fluid flowed through the flow-calming section to the test section and mixer, and then back into the storage tank.

\subsection{Flow-calming section}

A flow-calming section, similar to the one used by Ghajar and co-workers [3-6, 11-17] was installed prior to the test section to straighten the flow. The only difference was that the fluid first flowed through an additional $100 \mathrm{~mm}$ cavity filled with a soft nylon mesh (to mix the inlet flow to a uniform temperature), before it reached a Pt100 probe, where the average inlet temperature was measured. The acrylic tube had an inner diameter and length of $172 \mathrm{~mm}$ and $700 \mathrm{~mm}$, respectively, and an acetal disc was bolted to the inlet section to obtain a square-edged inlet.

\subsection{Test sections}

Two test sections, with inner diameters of $11.5 \mathrm{~mm}$ and $4 \mathrm{~mm}$, respectively, were used to investigate the influence of tube diameter and heating method. The test sections are shown 
schematically in Fig. 2, while the details of the thermocouple stations and pressure taps were given in Meyer and Everts [7] and Everts and Meyer [9], respectively.

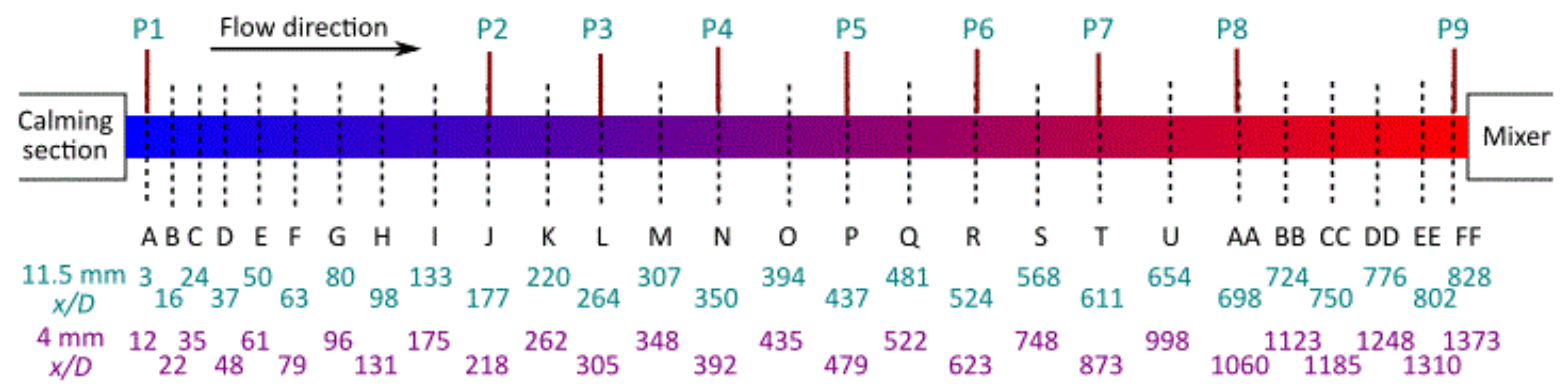

$\otimes$ Tail of flow direction

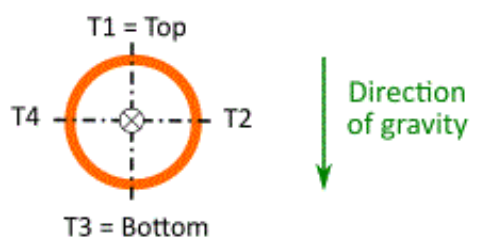

Fig. 2: Schematic representation of the test sections indicating the 27 thermocouples stations, A to $\mathrm{FF}$, on the $11.5 \mathrm{~mm}$ and $4 \mathrm{~mm}$ test sections, as well as the nine pressure taps, P1 to P9, on the $11.5 \mathrm{~mm}$ test section. The $x / D$ values of the thermocouples stations of both test sections, are also given. A cross-sectional view of the test section is included to illustrate the four thermocouples spaced around the outside periphery of the tube.

The $11.5 \mathrm{~mm}$ test section was manufactured from a hard-drawn copper tube with an inside diameter of $11.52 \mathrm{~mm}$, outside diameter of $12.7 \mathrm{~mm}$, and a length of $9.81 \mathrm{~m}$. To prevent possible upstream flow effects from influencing the measurements at the last measuring station (station FF), $300 \mathrm{~mm}$ was allowed between the last measuring station (at $x=9.5 \mathrm{~m}$ ) and the mixer (at $x=9.8 \mathrm{~m}$ ). The $4 \mathrm{~mm}$ test section was manufactured from a seamless $316 \mathrm{~L}$ stainless steel tube with an inner and outer diameter of $4 \mathrm{~mm}$ and $6 \mathrm{~mm}$, respectively, and a length of $6 \mathrm{~m}$. However, temperature measurements were only taken across the first $5.5 \mathrm{~m}$, up to station FF. The remaining $500 \mathrm{~mm}$ between the last measuring station and mixer was, as with the $11.5 \mathrm{~mm}$ test section, to prevent any upstream effects from influencing the measurements at the last thermocouple station.

The average surface roughness $(\varepsilon)$ of the $11.5 \mathrm{~mm}$ copper test section and $4 \mathrm{~mm}$ stainless steel test section was measured using a surface roughness tester, to be approximately $0.218 \mu \mathrm{m}$ and $0.138 \mu \mathrm{m}$, respectively. The relative surface roughness $(\varepsilon / D)$ was thus approximately $1.89 \times 10^{-5}$ and $3.45 \times 10^{-5}$, and for all practical purposes, both tubes can be considered as being smooth. The total length of the $11.5 \mathrm{~mm}$ and $4 \mathrm{~mm}$ test sections provided maximum length-to-inside diameter ratios $(x / D)$ of 828 and 1373 , respectively, while previous investigations by Ghajar and co-workers [6, 11, 12, 14-17] and Meyer and 
Olivier [18] had maximum values of 400 and 350, respectively. The test sections were thus 2-4 times longer than was in previous studies.

T-type thermocouples with a wire diameter of $0.25 \mathrm{~mm}$ and accuracy of $0.1^{\circ} \mathrm{C}$ were used to measure the surface temperatures at 27 selected axial positions on both test sections. The thermocouple stations were spaced closer to each other near the inlet of the test section to accurately obtain the temperature profile of developing flow, while the thermocouple stations were spaced further apart in the rest of the test section where the flow was expected to be fully developed. To compare the developing heat transfer results in the $4 \mathrm{~mm}$ and $11.5 \mathrm{~mm}$ test sections, the same non-dimensional axial positions were used on both test sections for $x / D<524$. As the diameter of the $4 \mathrm{~mm}$ test section was 2.88 times smaller than the $11.5 \mathrm{~mm}$ test section, the maximum length-to-inside diameter ratio $(x / D)$ was 1.66 times larger than that of the $11.5 \mathrm{~mm}$ test section. To obtain sufficient heat transfer results in the remaining part of the $4 \mathrm{~mm}$ test section, the thermocouples were located at $500 \mathrm{~mm}$ intervals for $524<x / D<873$, and at $250 \mathrm{~mm}$ intervals for $873<x / D<1373$. To investigate possible circumferential temperature distributions caused by free convection effects along the tube length, four thermocouples (spaced $90^{\circ}$ apart around the periphery) were used at each thermocouple station on the $11.5 \mathrm{~mm}$ test section, and on the $4 \mathrm{~mm}$ test section for $x / D<524$. The remaining thermocouple stations on the $4 \mathrm{~mm}$ test section contained thermocouples at the top and bottom of the test section, while the third thermocouple alternated between the left (T4 in Fig. 2) and right (T2 in Fig. 2) of the test section.

The thermocouples were soldered onto the $11.5 \mathrm{~mm}$ copper test section in a $0.3 \mathrm{~mm}$ indentation. As the wall thickness of the $4 \mathrm{~mm}$ stainless steel tube was $1 \mathrm{~mm}$, the thermocouples were glued into $0.5 \mathrm{~mm}$ indentations using a thermal adhesive with a thermal conductivity of $9 \mathrm{~W} / \mathrm{m} . \mathrm{K}$. A 3D printed jig was used to ensure that all the holes were drilled to the same depth. The thermocouples of both test sections were calibrated in-situ to an accuracy of $0.1^{\circ} \mathrm{C}$, by pumping water from the thermostat-controlled bath through the flowcalming section, test section and mixer, and back into the thermostat-controlled bath. Reference temperatures were obtained using Pt100 probes at the inlet of the flow-calming section, at the outlet of the mixer and in the thermostat-controlled bath. The temperature of the thermostat-controlled bath was varied between $20^{\circ} \mathrm{C}$ and $60^{\circ} \mathrm{C}$.

Two different heating methods were used in this study, because of the availability of equipment. To obtain a constant heat flux boundary condition in the $11.5 \mathrm{~mm}$ copper test section, four constantan wires (connected in parallel) with a diameter of $0.38 \mathrm{~mm}$ were coiled around the test section. A constant heat flux boundary condition was obtained in the $4 \mathrm{~mm}$ 
stainless steel test section, by passing current through the tube wall. The test section was electrically insulated with Kapton film before it was thermally insulated. Both test sections were thermally insulated with $120 \mathrm{~mm}$ thick Armaflex insulation with a thermal conductivity of $0.034 \mathrm{~W} / \mathrm{m} . \mathrm{K}$. The maximum heat loss was estimated with one-dimensional conduction heat transfer calculations to be less than $3 \%$ in both test sections. Using the criteria of Maranzana et al. [19], axial heat conduction was assumed to be negligible in both test sections, since the axial heat conduction number was orders of magnitude less than 0.01 .

\subsection{Mixer}

During laminar flow measurements, significant cross-sectional temperature gradients in the radial and tangential directions developed throughout the test section. Therefore, to obtain uniform tube outlet temperatures, a mixer was inserted after the test section to mix the water exiting the test section. The purpose of the mixer was twofold: to house the splitter plates, as well as to house the Pt100 probe that was used to measure the average outlet water temperatures. The mixer design was based on work done by Bakker et al. [20], who investigated laminar flow in static mixers with helical splitter plates.

\subsection{Experimental procedure}

Details of the experimental procedure were given in Meyer and Everts [7]. In the laminar flow regime, at very low Reynolds numbers, approximately 30 minutes was required to reach steady-state conditions. As the mass flow rate was increased, the time required for steadystate decreased to 20 minutes. Although the mass flow rates in the transitional flow regime were greater than in the laminar flow regime, up to 1 hour was required to reach steady-state due to the mass flow rate and temperature fluctuations inside the tube. In the quasi-turbulent and turbulent flow regimes, approximately 15 minutes was required for steady-state. After steady-state had been reached, 200 measuring points (temperature, pressure and mass flow rate) were captured at a frequency of $10 \mathrm{~Hz}$.

\subsection{Test matrix}

Experiments conducted at different mass flow rates and heat fluxes in the two test sections of $11.5 \mathrm{~mm}$ and $4 \mathrm{~mm}$, are summarised in Table 1 . The test matrix consisted of 1046 mass flow rate measurements, 89459 temperature measurements and 2906 pressure drop measurements. For a part of this study, experimental results from literature [21, 22] was used to complement our data in Table 1. The difference between the results of this study (Table 1) 
and literature (Table 2) is that the Prandtl number in this study varied between 3 and 7, while the Prandtl number of the experiments conducted by Strickland [21] was significantly higher and varied between 3 and 158. Although the experiments of Meyer and Abolarin [22] was also conducted using water, a larger tube diameter of $19 \mathrm{~mm}$ was used, which led to increased Grashof numbers. This study, together with literature, therefore ensures that a wider range of Prandtl number and Grashof number data was available.

Table 1: Experimental test matrix generated with water in the $4 \mathrm{~mm}$ and $11.5 \mathrm{~mm}$ test sections.

\begin{tabular}{cccccc}
\hline $\begin{array}{c}\text { Test } \\
\text { section }\end{array}$ & $\begin{array}{c}\text { Heat flux } \\
{\left[\mathrm{kW} / \mathrm{m}^{2}\right]}\end{array}$ & $\begin{array}{c}\text { Reynolds } \\
\text { number range }\end{array}$ & $\begin{array}{c}\text { Mass flow rate } \\
\text { measurements }\end{array}$ & $\begin{array}{c}\text { Temperature } \\
\text { measurements* }\end{array}$ & $\begin{array}{c}\text { Pressure drop } \\
\text { measurements }\end{array}$ \\
\hline \multirow{5}{*}{$11.5 \mathrm{~mm}$} & 0 & $507-14968$ & 178 & 16535 & 1095 \\
& 0.06 & $303-1793$ & 28 & 1344 & - \\
& 1 & $597-9280$ & 69 & 7521 & 552 \\
& 2 & $894-9376$ & 62 & 6758 & 496 \\
& 6.5 & $1061-9509$ & 55 & 5995 & 440 \\
& 8 & $460-9630$ & 111 & 5382 & 111 \\
$4 \mathrm{~mm}$ & 9.5 & $470-9600$ & 103 & 4944 & 103 \\
& 0.5 & $913-3303$ & 32 & 5232 & 109 \\
\hline & 1 & $965-6021$ & 67 & 3456 & - \\
& 2 & $947-7176$ & 66 & 7236 & - \\
& 4 & $1005-6963$ & 62 & 7128 & - \\
\hline & $885-7848$ & 57 & 6696 & - \\
\hline
\end{tabular}

*3 or 4 thermocouples per station

Table 2: Experimental test matrix of studies in literature with water, $60 \%$ ethylene glycol and $100 \%$ ethylene glycol in $15.88 \mathrm{~mm}$ and $19 \mathrm{~mm}$ test sections.

\begin{tabular}{|c|c|c|c|c|c|}
\hline \multirow{2}{*}{ Study } & \multicolumn{4}{|c|}{ Estimated number of mass flow rate measurements } & \multirow{2}{*}{$\operatorname{Pr}$} \\
\hline & Laminar & Transitional & Turbulent & Total & \\
\hline Strickland [21] & 13 & 37 & 32 & 82 & $3-158$ \\
\hline Meyer and Abolarin [22 & 32 & 30 & 154 & 216 & $3-7$ \\
\hline
\end{tabular}

\section{Data reduction}

As a constant heat flux boundary condition was applied to the test section, the average axial temperature of the water increased linearly. The mean fluid temperature, $T_{m}$, at a specific tube location, $x$, was obtained using a linear temperature distribution between the measured inlet, $T_{i}$, and measured outlet, $T_{o}$, temperatures of the fluid over length, $L$ :

\footnotetext{
${ }^{1}$ These experiments were conducted in the same laboratory at the University of Pretoria. Abolarin was a PhD student under the supervision of the second author.
} 


$$
T_{m}=\left(\frac{T_{o}-T_{i}}{L}\right) x+T_{i}
$$

The bulk fluid temperature, $T_{b}$, along a tube length, $L(x)$, measured from the inlet of the test section, was calculated as:

$$
T_{b}=\left(\frac{T_{o}-T_{i}}{L}\right) \frac{L(x)}{2}+T_{i}
$$

The properties of water (density, $\rho$, dynamic viscosity, $\mu$, thermal conductivity, $k$, specific heat, $C_{p}$, Prandtl number, $\operatorname{Pr}$, and thermal expansion coefficient, $\beta$ ) were determined using the thermophysical correlations for liquid water [23] at the bulk fluid temperature for the average properties, and at the mean fluid temperature for the local properties at a specific point $x$, measured from the inlet of the test section.

The Reynolds number, $R e$, was calculated as:

$$
R e=\frac{\dot{m} D}{\mu A_{c}}
$$

where $\dot{m}$ was the measured mass flow rate, $D$ was the measured inner-tube diameter, $\mu$ was the dynamic viscosity, and $A_{\mathrm{c}}$ the cross-sectional area of the test section $\left(A_{c}=\pi / 4 D^{2}\right)$.

The electrical input rate $\left(\dot{Q}_{e}=V I\right)$ remained constant, resulting in a constant heat flux. The heat transfer rate to the water, $\dot{Q}_{w}$, was determined from the measured mass flow rate, measured inlet and outlet temperatures of the water, and the specific heat which was calculated at the bulk fluid temperature:

$$
\dot{Q}_{w}=\dot{m} C_{p}\left(T_{o}-T_{i}\right)
$$

The heat transfer rate to the water, $\dot{Q}_{w}$, was continuously monitored by comparing it to the electrical input rate, $\dot{Q}_{e}$, which should ideally be equal since the test section was well insulated. The energy balance, $E B$, which ideally should be as close as possible to zero, was determined as:

$$
E B=\left|\frac{\dot{Q}_{e}-\dot{Q}_{w}}{\dot{Q}_{e}}\right| * 100=\left|\frac{V I-\dot{m} C_{p}\left(T_{o}-T_{i}\right)}{V I}\right| * 100
$$


The average energy balance of all the experiments that were conducted was less than $3 \%$, which was in good agreement with the calculations estimating the heat losses through the insulation material.

The heat flux, $\dot{q}$, on the inside of the tube wall was determined from the heat transfer rate to the water, $\dot{Q}_{w}$, and the inner surface area, $A_{s}$, of the test section along the heated length, $L$ :

$$
\dot{q}=\frac{\dot{Q}_{w}}{A_{s}}=\frac{\dot{m} C_{p}\left(T_{o}-T_{i}\right)}{\pi D L}
$$

The heat transfer rate to the water was used to determine the heat flux, since it was regarded as more accurate than the electrical input rate. As the energy balance was not zero, and some losses did occur to the ambient air, the electrical input rate was always slightly higher than the heat transfer rate to the water.

The average of the four (or three) temperature measurements at a station was used as the average outer surface temperature, $T_{s, o}$, at a specific thermocouple station:

$$
T_{s, o}=\frac{T_{1}+T_{2}+\cdots+T_{n}}{n}
$$

The thermal resistance across the tube wall, $R_{\text {tube }}$, was calculated using the following equation:

$$
R_{\text {tube }}=\frac{\ln \left(\frac{D_{o}}{D}\right)}{2 \pi k L}
$$

where $D_{o}$ and $D$ were the measured outside and inside diameters of the tube.

The thermal conductivity of copper is $401 \mathrm{~W} / \mathrm{m} . \mathrm{K}$, while the thermal conductivity of $316 \mathrm{~L}$ stainless steel is only $16.3 \mathrm{~W} / \mathrm{m} . \mathrm{K}$. The temperature difference across the tube wall, $\Delta T$, was calculated using Eq. (9), since the thermal resistance and heat input were known:

$$
\Delta T=\dot{Q}_{w} R_{t u b e}
$$

The thermal resistance in the $11.5 \mathrm{~mm}$ test section was calculated to be $4.05 \times 10^{-6}{ }^{\circ} \mathrm{C} / \mathrm{W}$, as the wall thickness was $0.6 \mathrm{~mm}$. Therefore, the temperature difference across the tube wall was approximately $0.004{ }^{\circ} \mathrm{C}$ when the maximum heat input $\left(3 \mathrm{~kW} / \mathrm{m}^{2}\right)$ was applied to the test section. The negligible temperature difference led to the assumption that the temperature on the inside surface of the test section was equal to the temperature measurement on the outside 
surface of the test section, since the temperatures in general could only be measured to an accuracy of $0.1{ }^{\circ} \mathrm{C}$. It was therefore assumed that the surface temperatures, determined from Eq. (7), was the average surface temperature on the inside of the tube at a measuring station in the $11.5 \mathrm{~mm}$ test section.

The thermal resistance in the $4 \mathrm{~mm}$ stainless steel tube was calculated to be $3.63 \times 10^{-4}$ ${ }^{\circ} \mathrm{C} / \mathrm{W}$, which is two orders of magnitude more than in the $11.5 \mathrm{~mm}$ copper tube. Although the thermocouples in the $4 \mathrm{~mm}$ test section were placed in an $0.5 \mathrm{~mm}$ deep indentation in the tube wall, the temperature difference across the remaining $0.5 \mathrm{~mm}$ was approximately $0.2{ }^{\circ} \mathrm{C}$ when the maximum heat input $\left(8 \mathrm{~kW} / \mathrm{m}^{2}\right)$ was applied to the test section. As this was not negligible, the temperature difference calculated using Eqs. (8) and (9) was subtracted from the measured surface temperatures (Eq. (7)), to obtain the inner surface temperatures, $T_{s}$, of the $4 \mathrm{~mm}$ test section:

$$
T_{s}=T_{s, o}-\Delta T=T_{s, o}-\dot{Q}_{w} R_{\text {tube }}
$$

The average surface temperature of the test section, $\bar{T}_{s}$, was calculated from all the temperature measurements on the test section, using the trapezoidal rule:

$$
\bar{T}_{s}=\frac{1}{L(x)} \int_{0}^{L(x)} T_{s}(x) d x
$$

The heat transfer coefficients, $h$, were then determined from the following equation, since the heat flux, $\dot{q}$, surface temperature, $T_{s}$, and mean fluid temperature, $T_{m}$, were known:

$$
h=\frac{\dot{q}}{\left(T_{s}-T_{m}\right)}
$$

The Nusselt numbers, $N u$, were determined from the heat transfer coefficients as follows:

$$
N u=\frac{h D}{k}
$$

The heat transfer results were also investigated in terms of the Colburn $j$-factor, to account for the variation in the Prandtl number:

$$
j=\frac{N u}{\operatorname{RePr}^{\frac{1}{3}}}
$$


The Graetz numbers, $G z$, were determined using the following equation:

$$
G z=\operatorname{RePr} \frac{D}{x}
$$

and the Grashof numbers, $G r$, as:

$$
G r=\frac{g \beta\left(T_{s}-T_{m}\right) D^{3}}{v^{2}}
$$

where $9.81 \mathrm{~m} / \mathrm{s}^{2}$ was used for the gravitational acceleration, $g$, and the kinematic viscosity was obtained from the density and dynamic viscosity $(v=\mu / \rho)$.

The modified Grashof numbers, $G r^{*}$, which are a function of heat flux instead of temperature difference, were the product of the Grashof numbers and Nusselt numbers and were determined as follows:

$$
G r^{*}=G r N u=\frac{g \beta \rho \dot{q} D^{4}}{v^{2} k}
$$

The Rayleigh numbers, $R a$, were determined as the product of the Grashof number and Prandtl numbers:

$$
\begin{aligned}
R a & =G r P r \\
R a^{*} & =G r^{*} P r
\end{aligned}
$$

The Richardson numbers, $R i$, were determined from the Grashof and Reynolds numbers:

$$
\begin{aligned}
R i & =\frac{G r}{R e^{2}} \\
R i^{*} & =\frac{G r^{*}}{R e^{2}}
\end{aligned}
$$

Eqs. (12) - (21) were for the local values at a specific axial position along the tube length. The average values along a tube length, $L(x)$, measured from the inlet of the test section, were obtained by using the bulk fluid temperature (Eq. (2)) and average surface temperature (Eq. (11)), instead of the mean fluid temperature (Eq. (1)) and local surface temperature (Eq. (10)).

In general, the percentage error of a measurement or calculated value $(M)$ was determined as \%error $=\left|M_{\text {exp }}-M_{c o r}\right| M_{c o r} \times 100$. The average percentage error was taken as the average of the absolute errors of the data points. 
The method suggested by Dunn [24] was used to calculate the uncertainties of the parameters obtained in the data reduction. All uncertainties were calculated within a $95 \%$ confidence interval and the uncertainty analysis details are given in Everts [10]. The Reynolds number uncertainties were approximately $1.5 \%$ in the laminar and turbulent flow regimes, and increased to $2 \%$ in the transitional flow regime due to the mass flow rate fluctuations that occurred in this flow regime. The laminar forced convection Nusselt number uncertainties were less than $10 \%$, while the laminar mixed convection uncertainties were less than 5\% and decreased with increasing heat flux. In the transitional flow regime, the uncertainties increased to approximately $10 \%$ (depending on the heat flux), due to the temperature fluctuations. The Nusselt number uncertainties in the turbulent flow regime increased with increasing Reynolds number, and the average Nusselt number uncertainty at a Reynolds number of 6000 was $13 \%$.

\section{Validation}

Extensive validation experiments were conducted and the details are given in Everts [10]. The heat transfer validation consisted of local laminar Nusselt number validations for forced and mixed convection conditions, as well as average laminar and turbulent Nusselt number validations.

It was very challenging to obtain forced convection conditions in macro tubes. The average fully developed Nusselt number $(50<x / D<827)$ in the $11.5 \mathrm{~mm}$ test section at a Reynolds number of 941 and heat flux of only $60 \mathrm{~W} / \mathrm{m}^{2}$, was found to be 4.75 . This was within $8.9 \%$ of the theoretical value of 4.36 for fully developed forced convection laminar flow. Forced convection conditions at a Reynolds number of 965 in the $4 \mathrm{~mm}$ test section were obtained at a heat flux of $1 \mathrm{~kW} / \mathrm{m}^{2}$. The average Nusselt number between $x / D=307$ and $x / D=1373$ was 4.5 , which was within $3.4 \%$ of the theoretical fully developed forced convection Nusselt number of 4.36. The results in both test sections also correlated well with the correlation of Shah and London [1], with an average deviation of $19 \%$ in the $11.5 \mathrm{~mm}$ test section, while the deviation between $x / D=567$ and $x / D=724$ was less than $3 \%$. An average deviation of $6 \%$ was obtained in the $4 \mathrm{~mm}$ test section, while the deviation between $x / D$ $=307$ and $x / D=1373$ was $1.7 \%$.

The local laminar Nusselt numbers in the $11.5 \mathrm{~mm}$ and $4 \mathrm{~mm}$ test sections for mixed convection conditions, were compared to the correlation of Morcos and Bergles [25], which is valid for fully developed flow. The results correlated well with an average deviation of $6 \%$ 
between $x / D=37$ and $x / D=827$ in the $11.5 \mathrm{~mm}$ test section, and average deviation of $4 \%$ between $x / D=79$ and $x / D=1373$ in the $4 \mathrm{~mm}$ test section.

Furthermore, the average laminar Nusselt numbers in the $11.5 \mathrm{~mm}$ and $4 \mathrm{~mm}$ test sections also correlated well with the correlation of Morcos and Bergles [25] with an average deviation of $2 \%$ and $4 \%$, respectively. The average turbulent Nusselt numbers in the $11.5 \mathrm{~mm}$ and $4 \mathrm{~mm}$ test sections correlated very well with the correlation of Ghajar and Tam [6], with an average deviation of less than $1 \%$ and $3.2 \%$, respectively. The results also correlated well with the correlation of Gnielinski [26] and the average deviation was 5\% and less than $1 \%$ in the $11.5 \mathrm{~mm}$ and $4 \mathrm{~mm}$ test sections, respectively.

\section{Comparison with maps from literature}

An evaluation was conducted to determine which possible criteria (Richardson number or existing flow regime maps) are suitable to predict the convection flow regime of the experimental data of this study. The criteria used to distinguish the forced and mixed convection laminar data was as proposed by Metais and Eckert [2], i.e. mixed convection occurs when the Nusselt numbers are $10 \%$ higher than the corresponding forced convection Nusselt numbers. When validating the experimental data taken in this study, it has been found [7] that only 5\% of our data fell into the forced convection flow regime. Therefore, in the evaluation that follows, $95 \%$ of our laminar data should fall in the mixed convection flow regime. In Fig. 3 - Fig. 5, the data of this study will be grouped by tube diameter ( $4 \mathrm{~mm}$ or $11.5 \mathrm{~mm}$ ), as well as which data (mostly) were mixed convection data.

The criteria proposed by Metais and Eckert [2] requires the corresponding forced convection Nusselt number obtained using forced convection correlations, however, such correlations are not available in the transitional flow regime. The experimental data in Fig. 3

- Fig. 5 were therefore coloured according to the ratio of $h_{t} / h_{b}$, since this can be used to gain insight into the free convection effects in all flow regimes. As will be discussed in Section 6.1, this criterion is suitable to compare results in a single test section, but not when different tube diameters and test fluids are used.

The Richardson number, which represents the ratio of the buoyancy forces to the viscous forces, is a criterion that can be used to determine whether free convection is significant. The flow could be expected to be dominated by forced convection when the Richardson number is less than 0.1 , and by free convection when the Richardson number is greater than 10 . When the Richardson number varies between 0.1 and 10 , both free and forced convection effects are significant and the flow is expected to be in the mixed convection flow regime [27]. Fig. 3 
compares the Reynolds numbers as a function of Richardson number of the experimental data (coloured according to the values of $h_{t} / h_{b}$ ) in the $4 \mathrm{~mm}$ and $11.5 \mathrm{~mm}$ test sections. The black dotted lines indicate the Richardson criteria for mixed convection $(0.1 \leq R i \leq 10)$. Although 95\% of the laminar experimental data was supposed to be in the mixed convection region, it follows from this figure that it fell incorrectly into the forced convection region.

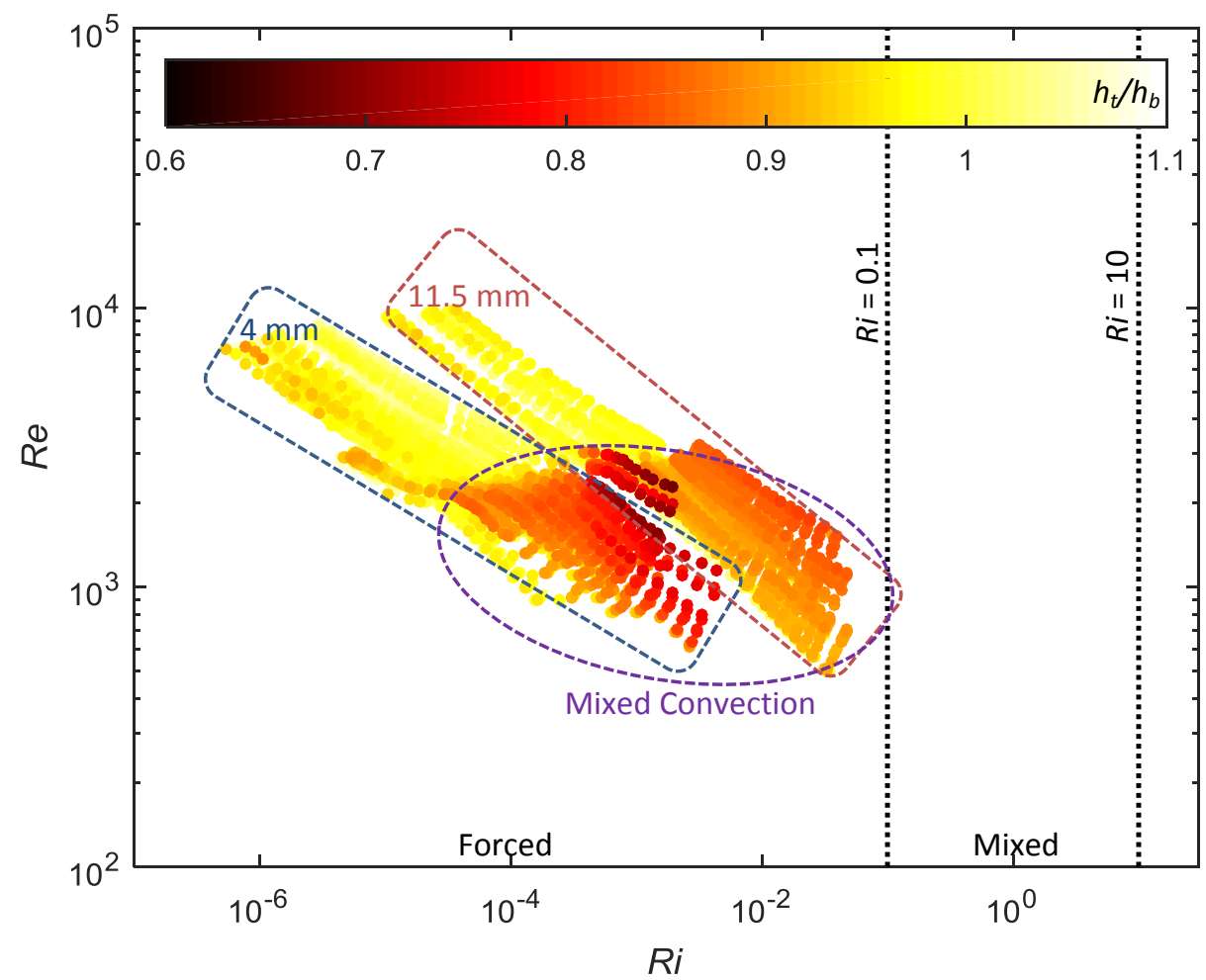

Fig. 3: Reynolds number as a function of Richardson number for the experimental data in the $4 \mathrm{~mm}$ and $11.5 \mathrm{~mm}$ test sections. The horizontal colour bar is coloured according to $h_{t} / h_{b}$. The mixed convection data is identified in the dotted purple oval.

The experimental data of this study were plotted (and coloured according to $h_{t} / h_{b}$ ) on the flow regime map of Metais and Eckert [2] in Fig. 4. This flow regime map was developed for horizontal circular tubes with $10^{-2}<\operatorname{Pr}(x / D)<1$, using a constant surface temperature boundary condition. Exact correlation was therefore not expected, since a constant heat flux boundary condition was used in this study and the values of $\operatorname{Pr}(x / D)$ varied between 160 and 8550.

As all the experimental data fell to the left of the forced/mixed convection boundary (indicated by the green line) in Fig. 4, it is expected to be forced convection data. However, using their criteria $\left(\mathrm{Nu} / \mathrm{Nu} u_{F C}>1.1\right)$, 95\% of the laminar data of this study is mixed convection data. It was therefore concluded that this map did not accurately predict the flow regimes of the experimental data of this study. 


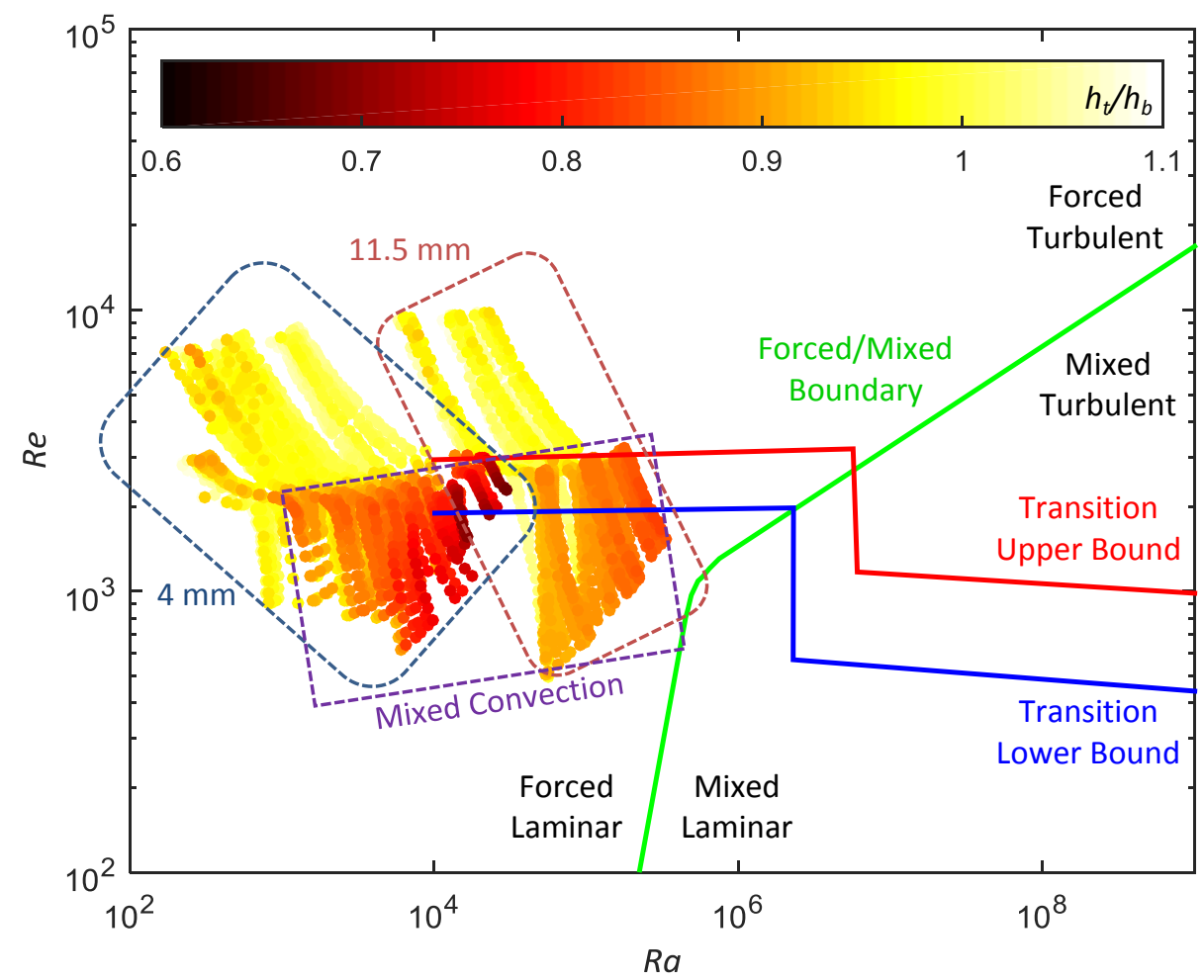

Fig. 4: Comparison of the flow regime map of Metais and Eckert [2] and the experimental data in the $4 \mathrm{~mm}$ and $11.5 \mathrm{~mm}$ test sections. The horizontal colour bar is coloured according to $h_{t} / h_{b}$. The mixed convection data is identified in the dotted purple rectangle.

The experimental data of this study, as well as the experimental data of Strickland [21], were plotted (and coloured according to $h_{t} / h_{b}$ ) on the unified flow regime map of Tam et al. [5] in Fig. 5. This flow regime map was developed for horizontal tubes with a constant heat flux boundary condition. The boundary between forced and mixed convection was independent of the inlet geometry, while separate upper and lower boundaries of the transitional flow regime were included for the different inlet geometries. For clarity purposes, only the transitional flow regime boundaries of the square-edged inlet were included in Fig. 5, since this inlet geometry was used in this study.

From Fig. 5 it follows that this flow regime map was primarily for Rayleigh numbers in the order of $10^{5}$ to $10^{8}$, which is high. This map was developed using the experimental data of Ghajar and Tam [6], who used the experimental data of Strickland [21] for the squareedged inlet. An analysis of the experiments conducted for the square-edged inlet [21] shows that distilled water was used for turbulent Reynolds numbers $(3639<R e<50529$ and $3.4<\operatorname{Pr}<6.2$ ), full concentration ethylene glycol was used in the laminar flow regime $(281<\operatorname{Re}<3328$ and $96<\operatorname{Pr}<158)$ and a mixture of $60 \%$ ethylene glycol (by mass fraction) and water was used for Reynolds numbers between 1180 and 12 456. This covered 
the entire transitional flow regime as well as part of the laminar and quasi-turbulent flow regimes, and the Prandtl number varied between 12.9 and 146. The mixed convection boundary in the laminar and transitional flow regimes, was therefore developed using experimental data with Prandtl numbers between 12.9 and 158, while the Prandtl number in this study varied between 3 and 7 .

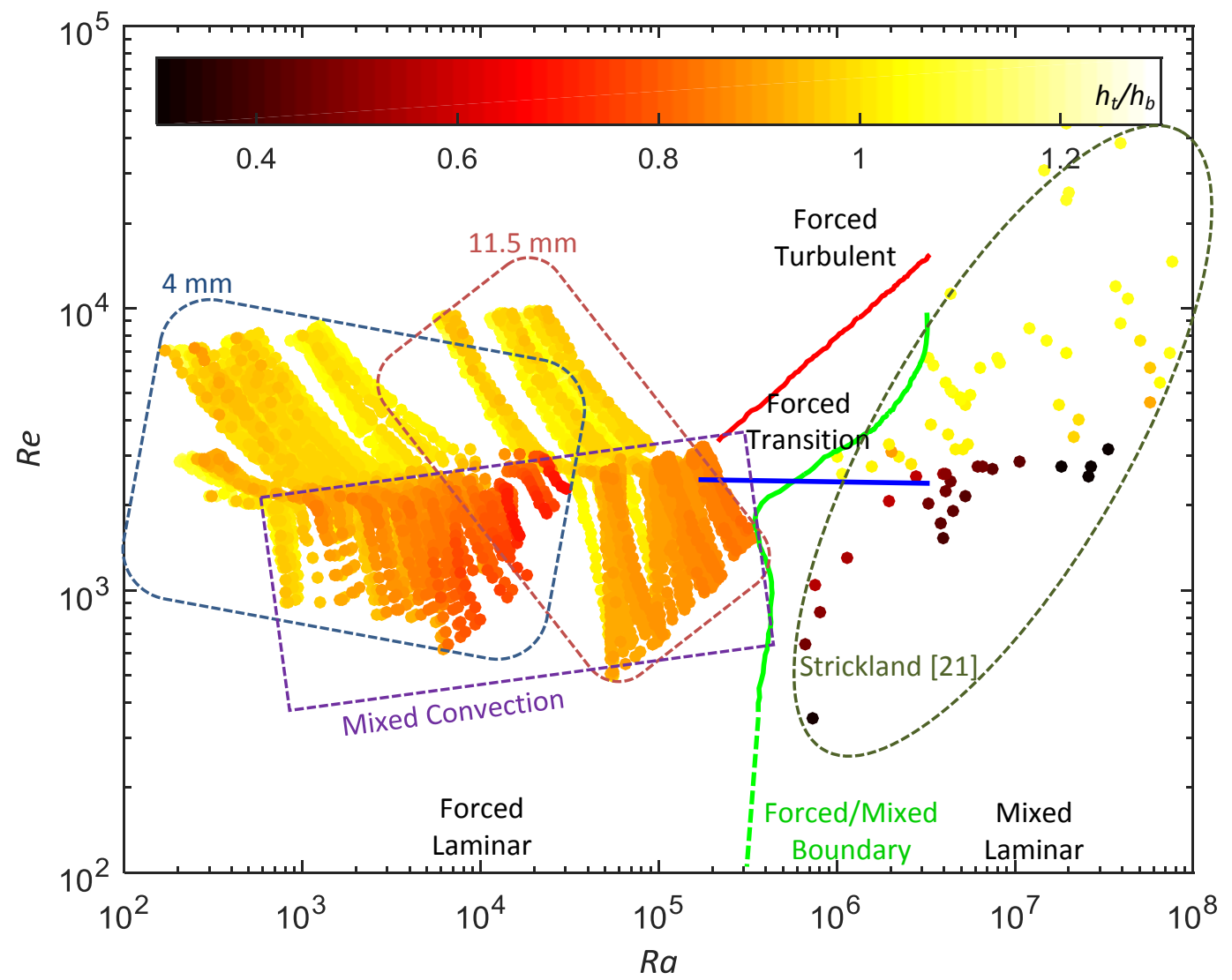

Fig. 5: Comparison of the flow regime map of Tam et al. [5] with the experimental data of the $4 \mathrm{~mm}$ and $11 \mathrm{~mm}$ test sections, as well as the experimental data of Strickland [21]. The horizontal colour bar is coloured according to $h_{t} / h_{b}$. The mixed convection data of this study is identified in the purple dotted rectangle.

As the Grashof number is a strong function of the inner tube diameter $\left(G r \propto D^{3}\right)$, free convection effects increased significantly with increasing tube diameter. The test section used by Strickland [21] had a relatively large inner diameter of $15.8 \mathrm{~mm}$ and the Grashof number varied between 1000 and $2.5 \times 10^{5}$, which can be expected to be up to 62 times greater than when a $4 \mathrm{~mm}$ tube is used. Furthermore, the Grashof number is also a function of the surface-fluid temperature difference, which was significantly higher for ethylene glycol than for water, due to the low thermal conductivity and specific heat, as well as the high viscosity of ethylene glycol. This also led to significantly lower values of $h_{t} / h_{b}$ compared to water. From the experimental data of Strickland [21] in Fig. 5, it follows that $h_{t} / h_{b}$ decreased to as low as 0.3 in the laminar flow regime, while it did not decrease below 0.7 in our data. 
The high Prandtl numbers of ethylene glycol, combined with the relatively high Grashof numbers (due to the large tube diameter and surface-fluid temperature difference), led to Rayleigh numbers between $6.7 \times 10^{5}$ and $7.4 \times 10^{7}$ in the study of Strickland [21]. This is of significant importance as the Rayleigh number is used on the $x$-axis of the flow regime map to distinguish between forced and mixed convection data. From Fig. 5 it follows that this flow regime map was able to accurately predict the convection flow regime of the experimental results of Strickland [21]. However, it incorrectly predicted that all the data of this study should be in the forced convection flow regime (Rayleigh numbers in the order of $10^{5}$ and less).

\section{Proposed flow regime maps}

From Fig. 3 - Fig. 5, it was concluded that there was no suitable criteria or flow regime map in literature to accurately predict the convection flow regime of the experimental data of this study. New, easy-to-use flow regime maps, which are valid for developing and fully developed flow using different test fluids and tube diameters, were therefore developed in this paper.

\subsection{Flow regime map criteria}

Metais and Eckert [2] defined the boundary between forced and mixed convection as the location were the heat transfer coefficients were $10 \%$ greater than the corresponding forced convection case $\left(N u / N u_{F C}>1.1\right)$, while Tam et al. [5] defined it as the location where $h_{t} / h_{b}$ decreased below 0.8 . To evaluate the suitability of the two criteria, the fully developed Nusselt numbers were divided by 4.36 (fully developed forced convection laminar flow) and plotted against $h_{t} / h_{b}$ in Fig. 6 . The $10 \%$ increase in heat transfer coefficient criteria, $N u / N u_{F C}$ $>1.1$, which was used by Metais and Eckert [2] is indicated by the dotted black horizontal line. The dotted green vertical line indicates the heat transfer coefficient ratio criteria, $h_{t} / h_{b}<$ 0.8 , which was used by Tam et al. [5].

From Fig. 6 it follows that as the tube diameter was increased from $4 \mathrm{~mm}$ to $19 \mathrm{~mm}$, using water as the test fluid (the data produced in our laboratory), $N u / N u_{F C}$ increased significantly from 1 to approximately 4 . However, there was only a slight decrease in $h_{t} / h_{b}$ and it did not decrease below 0.8 in the $11.5 \mathrm{~mm}$ and $19 \mathrm{~mm}$ test sections. Although $N u / N u_{F C}$ of the results of Strickland [21], who used pure ethylene glycol in a $15.8 \mathrm{~mm}$ test section, was approximately between the results of the $11.5 \mathrm{~mm}$ and $19 \mathrm{~mm}$ test sections, $h_{t} / h_{b}$ was significantly lower. This was due to the increased circumferential and axial temperature 
differences, which was caused by the low thermal conductivity and specific heat, as well as the high viscosity of ethylene glycol.

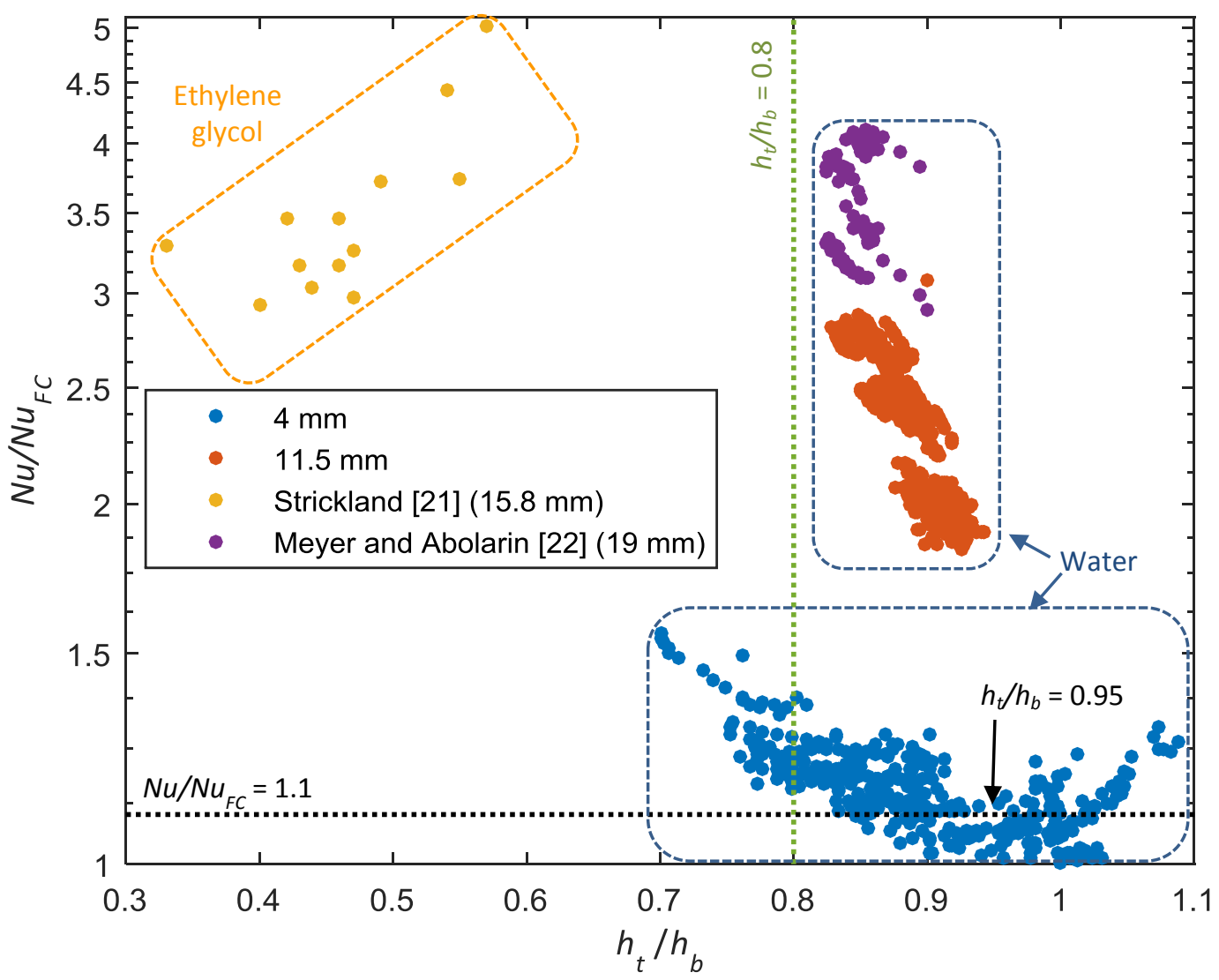

Fig. 6: Comparison of the experimental data of this study and literature $[21,22]$ in terms of $N u / N u_{F C}$ (where $\left.N u_{F C}=4.36\right)$ against $h_{t} / h_{b}$ at different heat fluxes, for different tube diameters and test fluids.

As indicated by the Grashof number, free convection effects increased with increasing tube diameter, which explains why $N u / N u_{F C}$ increased. As expected, the values of $h_{t} / h_{b}$ in the $19 \mathrm{~mm}$ test section were less than in the $11.5 \mathrm{~mm}$ test section, however, the minimum $h_{t} / h_{b^{-}}$ value in the $4 \mathrm{~mm}$ test section was less that in the $11.5 \mathrm{~mm}$ and $19 \mathrm{~mm}$ test sections. There was thus no distinct trend between $h_{t} / h_{b}$ and tube diameter. From Fig. 6 it also follows that $h_{t} / h_{b}$ was very dependent on the fluid properties, and differed significantly when results of different test fluids, for example water and ethylene glycol, were compared. Furthermore, it has been found that the heat transfer coefficient ratio criteria, $h_{t} / h_{b}<0.8$, was too conservative for our experimental data. At $h_{t} / h_{b}=0.8, N u / N u_{F C}$ in the $4 \mathrm{~mm}$ test section ranged between 1.16 and 1.4, which means that the Nusselt numbers were between $16 \%$ and $40 \%$ greater than the corresponding forced convection case. Furthermore, $h_{t} / h_{b}$ in the $11.5 \mathrm{~mm}$ test section did not decrease below 0.83 , while $N u / N u_{F C}$ varied between 1.9 and 2.9. From this figure it follows that $h_{t} / h_{b} \leq 0.95$, was more appropriate for the results obtained 
using water, since this corresponds to the point where $N u / N u_{F C}$ increased above 1.1 in the $4 \mathrm{~mm}$ test section. Although the flow regime maps of Metais and Eckert [2] and Tam et al. [5], as well as the Richardson number criteria predicted our data as forced convection, free convection effects were present in $95 \%$ of our laminar experimental data [7].

It can be concluded from Fig. 6 that although $h_{t} / h_{b}$ was an appropriate criterion for Ghajar and Tam [6], the $10 \%$ increase in heat transfer coefficient criteria, $N u / N u_{F C}>1.1$, was more suitable for our study, since it increased with increasing tube diameter and heat flux, which is known to increase free convection effects. It should be noted that $h_{t} / h_{b}$ is a valuable tool to gain insight in the local free convection effects along the test section and how it is influenced by Reynolds number and heat flux, but it seems as if care should be taken when different tube diameters and especially test fluids are compared, since it significantly affects the values of $h_{t} / h_{b}$.

\subsection{Flow regime map for fully developed flow}

In order to find a suitable parameter to be used on the $x$-axis of a graph with Reynolds number on the $y$-axis, the fully developed laminar experimental data of the $4 \mathrm{~mm}$ and $11.5 \mathrm{~mm}$ test sections were plotted as a function of Grashof number, Rayleigh number, Richardson number, and Richardson-Prandtl product in Fig. 7. The experimental data of Strickland [21] and Meyer and Abolarin [22], were also included to ensure that the flow regime map is valid for different tube diameters and test fluids. As this was for fully developed flow only, the theoretical fully developed forced convection Nusselt number of 4.36, was used for the forced convection Nusselt number reference, $N u_{F C}$. The results were thus coloured according to $N u / 4.36$. The laminar data was identified using Eq. (22) [8],

$$
R e<R e_{c r}=\left(0.1972 \frac{x}{D}+1156.7\right) G r^{0.077}
$$

while the fully developed data was identified using Eq. (23) [7],

$$
L t_{F D}=D\left(\frac{130 R e}{G r^{0.4} \operatorname{Pr}^{0.65}}\right)^{10 / 13}
$$

and the data in the quasi-turbulent and turbulent flow regimes, using Eq. (24) [8]:

$$
R e_{q t}=2504 G r^{0.018}
$$


The red dotted blocks in Fig. 7 indicate that not all the parameters were suitable to use on the $x$-axis, since 'red data' (mixed convection) fell onto regions of 'blue data' (forced convection). From this figure it follows that the Rayleigh number (Fig. 7(b)) and Richardson-Prandtl product (Fig. 7(d)) would be suitable, since the colour changed gradually from dark blue (forced convection) to red (mixed convection) as free convection effects increased. As free convection effects increased horizontally (indicated by the black arrows) when the Rayleigh number (Fig. 7(b)) was used and not diagonally as when $\operatorname{RiPr}$ (Fig. 7(d)) was used, it was decided to use Rayleigh number on the $x$-axis of the flow regime maps for fully developed flow. Although the Rayleigh number was also used on the $x$-axis of the flow regime maps of Metais and Eckert [2] and Tam et al. [5], it was found that the predicted forced/mixed convection boundaries were not suitable for the experimental data of this study.

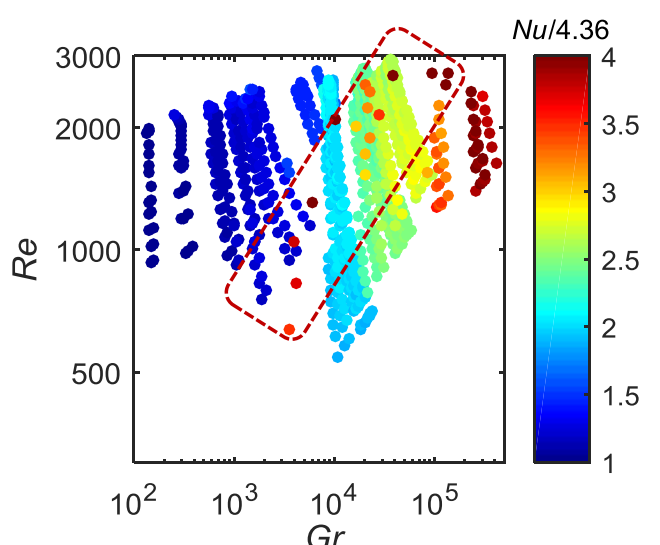

(a)

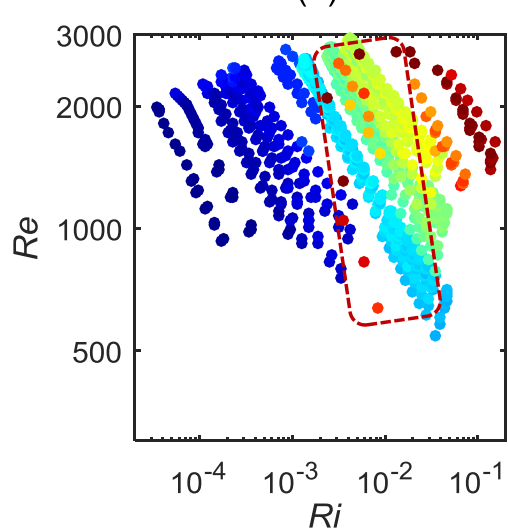

(c)

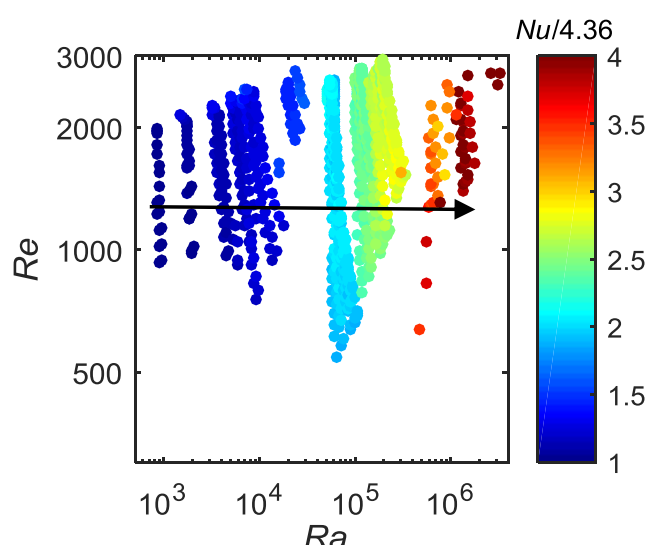

(b)

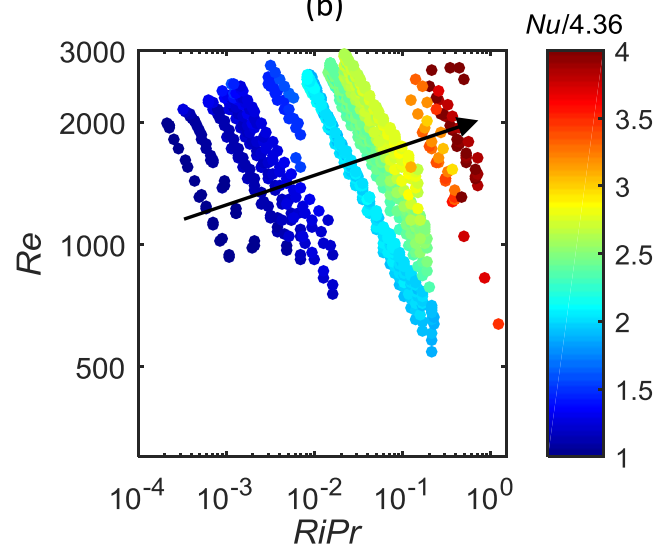

(d)

Fig. 7: Fully developed experimental data of this study and literature [21, 22] plotted as a function of (a) $G r$, (b) $R a$, (c) $R i$ and (d) RiPr. The data is coloured according to Nu/4.36.

To develop a flow regime map that is valid for all flow regimes, Eqs. (22) and (24) was used to obtain the upper and lower boundaries of the transitional flow regime. However, Eq. (24) was multiplied by 1.2 to ensure a more conservative value for the end of the transitional flow regime. As free convection effects were negligible in the turbulent flow regime, 
$N u / N u_{F C}$ was set to 1 for all Reynolds numbers greater than this boundary $\left(R e_{q t}\right)$, and added to the laminar results of Fig. 7 in Fig. 8(a).

As far as we have determined, no experimental data in the transitional flow regime are available that specifically distinguishes between forced and mixed convection. Therefore, the experimental data in the transitional flow regime (between the dotted green and red lines) at heat fluxes of $0.5 \mathrm{~kW} / \mathrm{m}^{2}$ and $1 \mathrm{~kW} / \mathrm{m}^{2}$ in the $4 \mathrm{~mm}$ test section were included, since it was known that forced convection conditions $\left(\mathrm{Nu} / \mathrm{Nu} u_{F C}=1\right)$ existed at these two heat fluxes [7]. This data was used as a guideline to obtain the forced/mixed convection boundary in the transitional flow regime. The experimental data in the transitional flow regime in the $11.5 \mathrm{~mm}$ test section, as well as at other heat fluxes in the $4 \mathrm{~mm}$ test section, was excluded since there is currently no correlation which can be used as a forced convection reference to calculate $N u / N u_{F C}$. To obtain a flow regime map that is a function of heat flux and not temperature difference, the data were also plotted as a function of the modified Rayleigh number, $R a^{*}$, in Fig. 8(b).

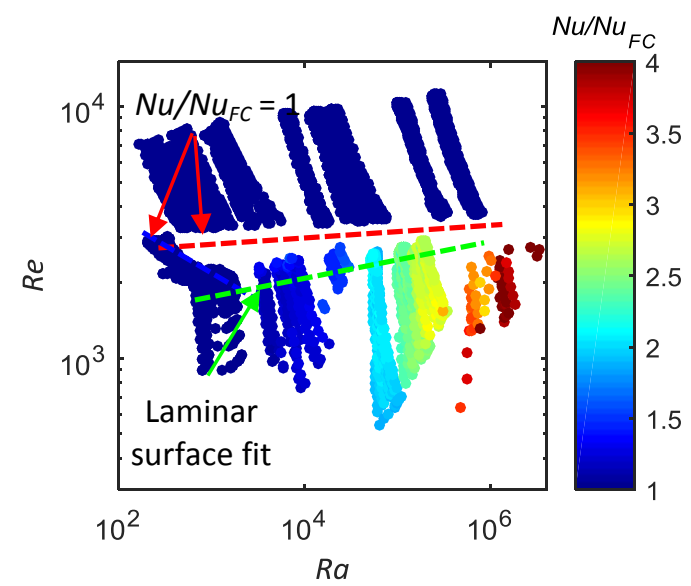

(a)

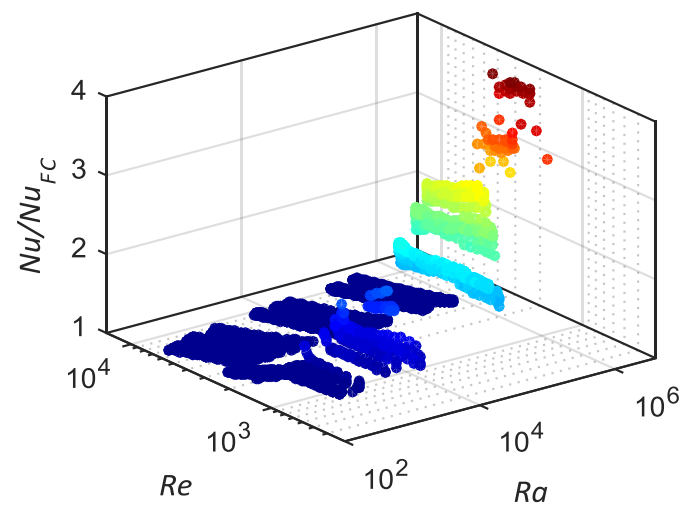

(c)

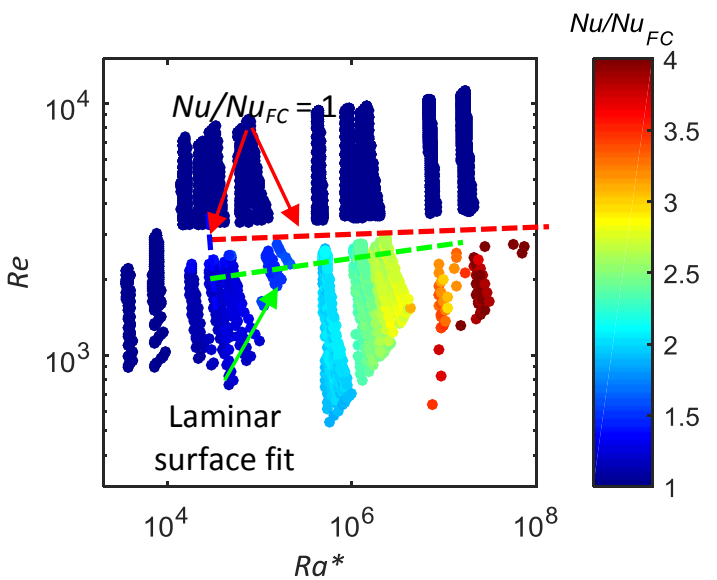

(b)

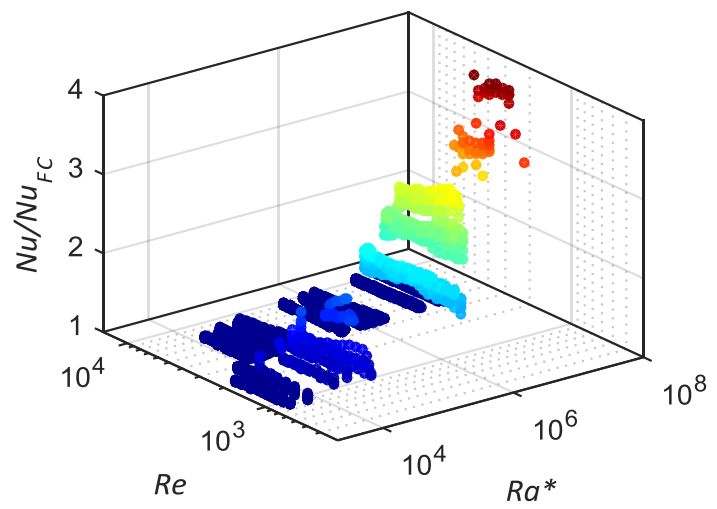

(d)

Fig. 8: Laminar, quasi-turbulent, turbulent and forced convection transitional data of this study and literature [21, 22] plotted as a function of Reynolds number against $R a$ and $R a^{*}$. The data is coloured according to $N u_{F C}$, where $N u_{F C}=4.36$ for all data below the dotted green line. For all other data, $N u / N u_{F C}=1$, where $N u_{F C}$ represents the corresponding forced convection Nusselt number from general literature. 
Fig. 8(c) and (d) are three dimensional plots of the results in Fig. 8(a) and (b). To generate the full flow regime map, a surface fit was done through the laminar heat transfer data, using $R a$ and $R a^{*}$, respectively, on the $x$-axis, Reynolds number on the $y$-axis and $N u / N u_{F C}$ on the $z$-axis. Another surface fit was then done through the data on the $R e_{c r}$-line (using the laminar surface fit) and the $R e_{q t}$-line (using $N u / N u_{\mathrm{FC}}=1$ ) to fill the transitional flow regime gap in Fig. 8(a) and (b).

Fig. 9 and Fig. 10 contain the flow regime maps for fully developed flow in terms of $R a$ and $R a^{*}$, respectively. In both flow regime maps, $N u_{F C}=4.36$ for all data below the $R e_{c r}$-line (Eqs. (25) and (29)), while $N u_{F C}$ is the corresponding forced convection Nusselt number from general literature for all data above the $R e_{q t}$-line (Eqs. (26) and (30)). In the transitional flow regime ( $R e_{c r}<R e<R e_{q t}$, thus all the data between Eqs. (25) and (26), and Eqs. (29) and (30)), correlations are not available for specifically forced convection and mixed convection data. Therefore $N u / N u_{F C}$ only gives an estimate (as it was not based on measurements) of whether free convection effects can be expected or not, and not the actual Nusselt number values. From these figures it follows that $R a<4970$ and $R a^{*}<2.40 \times 10^{4}$ (indicated by the dotted yellow lines), can be used as Reynolds number independent criteria $\left(N u / N u_{F C}=1.1\right)$ that will ensure that the flow regime will most probably be forced convection. More conservative criteria $\left(N u / N u_{F C}=1\right)$ will be $R a<2520$ and $R a^{*}<1.02 \times 10^{4}$.

The equations of the transitional flow regime boundaries and the forced/mixed convection boundaries of the fully developed flow regime maps in Fig. 9 and Fig. 10, are summarised in Table 3.

Table 3: Equations of the transitional flow regime boundaries and forced/mixed convection boundaries, and ranges of the flow regime maps as a function of $R a$ and $R a^{*}$.

\begin{tabular}{|c|c|c|c|}
\hline & & Correlation & Eq. \\
\hline \multirow{4}{*}{$\begin{array}{c}R a \\
\text { (Fig. 9) }\end{array}$} & $R e_{c r}$ & $R e_{c r}=1272 R a^{0.06834}$ & $(25)$ \\
\hline & $R e_{q t}$ & $R e_{q t}=2846 R a^{0.02177}$ & $(26)$ \\
\hline & $\operatorname{Re}<\operatorname{Re} e_{c r}$ & $F C / M C=7.278 \times 10^{7} R a^{-1.212}-202.3$ & (27) \\
\hline & $\operatorname{Re}_{c r}<\operatorname{Re}<\operatorname{Re} e_{q t}$ & $F C / M C=-1.123 \times 10^{5} R a^{-0.4958}+3950$ & $(28)$ \\
\hline \multirow{4}{*}{$\begin{array}{c}R a^{*} \\
\text { (Fig. 10) }\end{array}$} & $R e_{c r}$ & $R e_{c r}=1730.9 R a^{* 0.0549}$ & (29) \\
\hline & $R e_{q t}$ & $R e_{q t}=3056.4 R a^{* 0.0217}$ & $(30)$ \\
\hline & $\operatorname{Re}<\operatorname{Re} e_{c r}$ & $F C / M C=2.73 \times 10^{9} R a^{*-1.39}+75.5$ & (31) \\
\hline & $\operatorname{Re}_{c r}<\operatorname{Re}<\operatorname{Re} e_{q t}$ & $F C / M C=-3.338 \times 10^{4} R a^{*-0.3112}+3839$ & $(32)$ \\
\hline & Ranges & $\begin{array}{c}546 \leq R e \leq 11247 \\
3 \leq \operatorname{Pr} \leq 139.4 \\
26 \leq G r \leq 4.2 \times 10^{5} \\
561 \leq G r^{*} \leq 7 \times 10^{6}\end{array}$ & \\
\hline
\end{tabular}




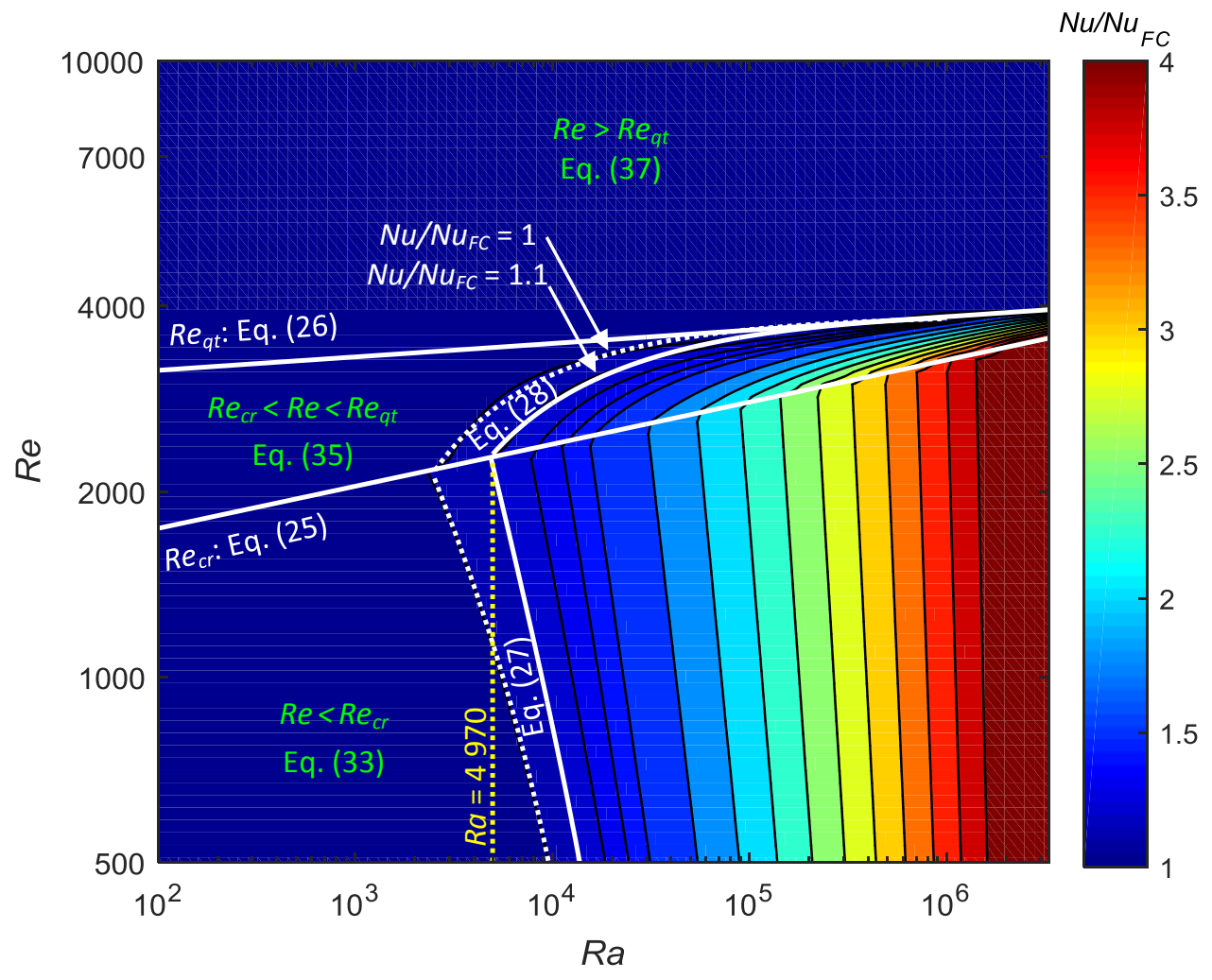

Fig. 9: Flow regime map for fully developed flow as a function of $R e$ and $R a$. $N u_{F C}=4.36$ for all data below Eq. (25), while $N u_{F C}$ is the corresponding forced convection Nusselt number from general literature for all data above Eq. (26). In the transitional flow regime $\left(R e_{c r}<R e<R e_{q t}\right), N u / N u_{F C}$ only gives an estimate of whether free convection effects can be expected or not, and not the actual Nusselt number values.

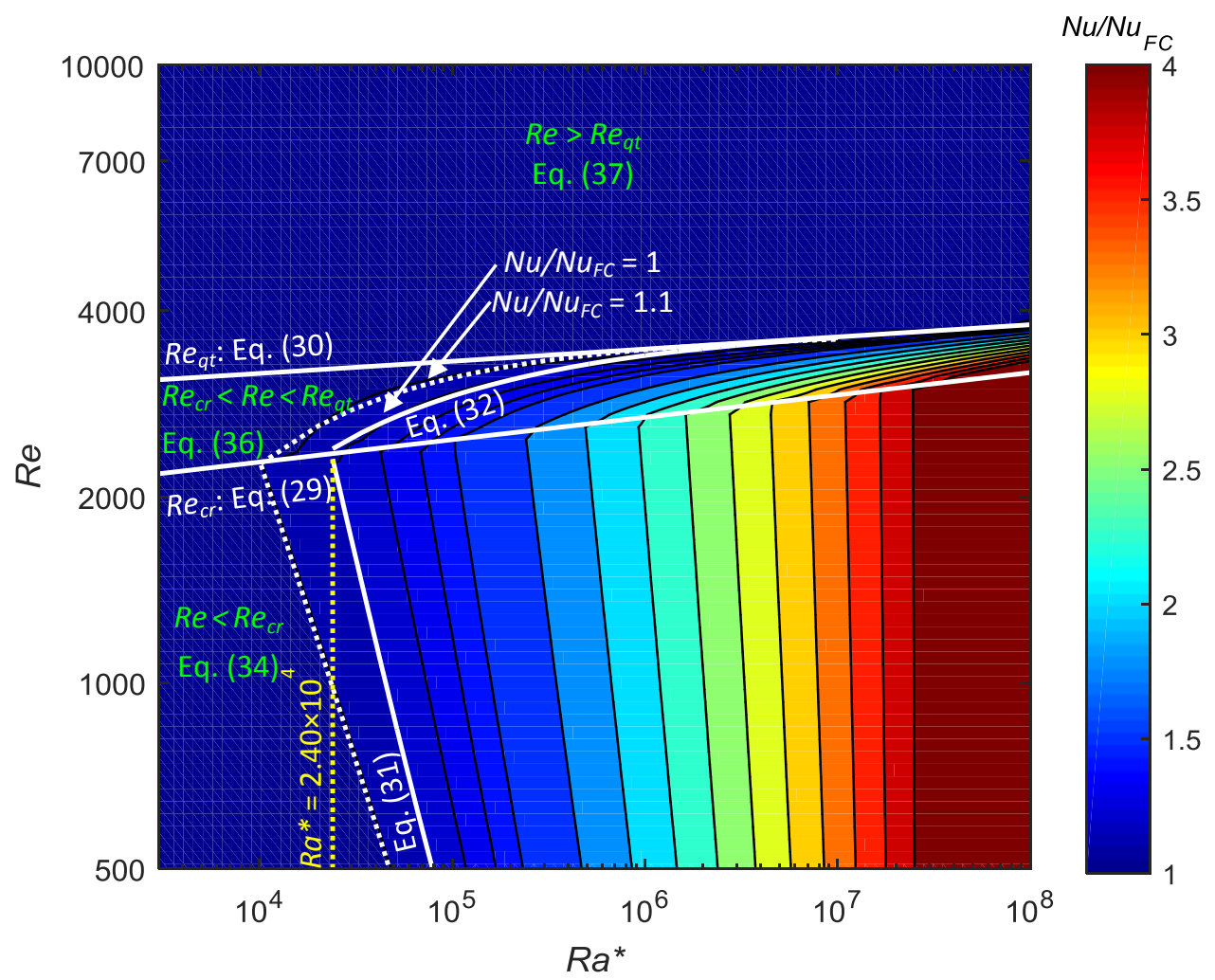

Fig. 10: Flow regime map for fully developed flow as a function of $R e$ and $R a^{*}$. $N u_{F C}=4.36$ for all data below Eq. (29), while $N u_{F C}$ is the corresponding forced convection Nusselt number for all data above Eq. (30). In the transitional flow regime $\left(R e_{c r}<R e<R e_{q t}\right), N u / N u_{F C}$ only gives an estimate of whether free convection effects can be expected or not, and not the actual Nusselt number values. 
Table 4: Ranges and correlations of proposed average Nusselt number correlations. As Eqs. (33)-(37) are average Nusselt number correlations, $\operatorname{Pr}, \operatorname{Re}, \mathrm{Gr}$ and $\mathrm{Gr}$ * are evaluated at the bulk fluid temperature.

\begin{tabular}{|c|c|c|c|}
\hline & Range & Correlation & Eq. \\
\hline \multirow{2}{*}{ 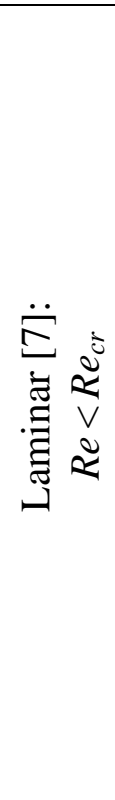 } & \multirow{2}{*}{ 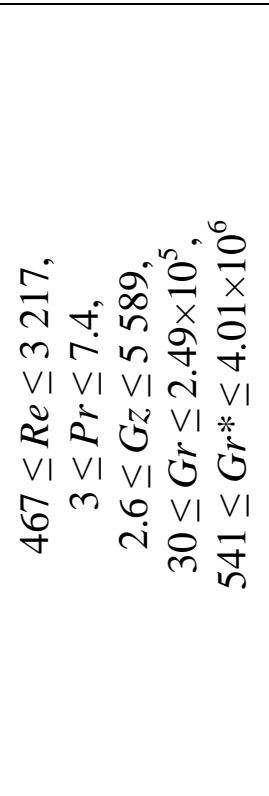 } & $\begin{array}{c}\overline{N u}=4.36+\overline{N u}_{1}+\overline{N u}_{2} \\
\overline{N u}_{1}=\frac{1}{L}\left(-0.84 \operatorname{Pr}^{-0.2} L t_{M C D}+0.72(R e D)^{0.54} \operatorname{Pr}^{0.34} L t_{M C D}^{0.46}\right) \\
\overline{N u}_{2}=\frac{1}{L}\left(0.207 G r^{0.305}-1.19\right) \operatorname{Pr}^{0.42}(R e D)^{-0.08}\left(L-L t_{M C D}\right) \\
L t_{M C D}=\frac{2.4 \operatorname{RePr}^{0.6} D}{G r^{0.57}}\end{array}$ & $(33)$ \\
\hline & & $\begin{array}{c}\overline{N u}=4.36+\overline{N u}_{1}+\overline{N u}_{2} \\
\overline{N u}_{1}=\frac{1}{L}\left(-0.84 \operatorname{Pr}^{-0.2} L t_{M C D}+0.72(\operatorname{ReD})^{0.54} \operatorname{Pr}^{0.34} L t_{M C D}^{0.46}\right) \\
\overline{N u}_{2}=\frac{1}{L}\left(0.202 G r^{* 0.254}-1.23\right) \operatorname{Pr}^{0.39}(\operatorname{ReD})^{-0.06}\left(L-L t_{M C D}\right) \\
L t_{M C D}=\frac{2.1 \operatorname{RePr^{0.6}D}}{G r^{* 0.45}}\end{array}$ & (34) \\
\hline 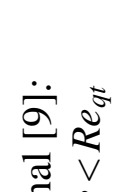 & 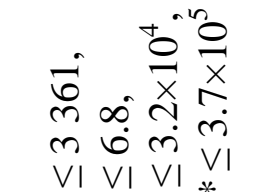 & $\overline{N u}=(0.00108 R e-2.49) G r^{-0.04} P^{2}$ & $(35)$ \\
\hline 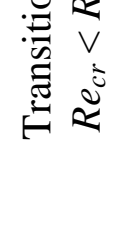 & 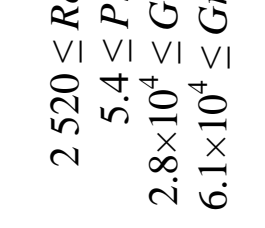 & $\overline{N u}=(0.00087 R e-2.01) G r^{*-0.01} \operatorname{Pr}^{2}$ & $(36)$ \\
\hline 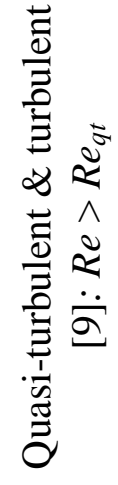 & 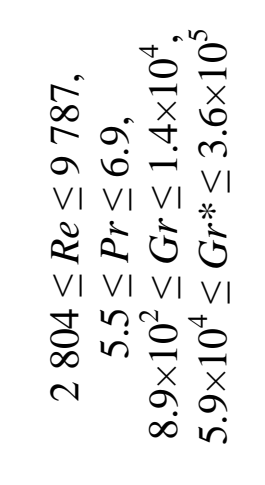 & $\overline{N u}=\left(0.417(R e-1000)^{0.499}-8.2\right) \operatorname{Pr}^{0.42}$ & $(37)$ \\
\hline
\end{tabular}

Proposed average Nusselt number correlations [7, 9], are also included in these flow regime maps (as well as the flow regime maps for developing flow in Section 6.3), and the correlations, as well as their ranges, are summarised in Table 4. However, it should be noted that these correlations were developed using water data only, while the flow regime map is valid for high Prandtl number fluids as well. Therefore, other suitable Nusselt number 
Table 4: Ranges and correlations of proposed average Nusselt number correlations. As Eqs. (33)-(37) are average Nusselt number correlations, Pr, Re, Gr and Gr* are evaluated at the bulk fluid temperature.

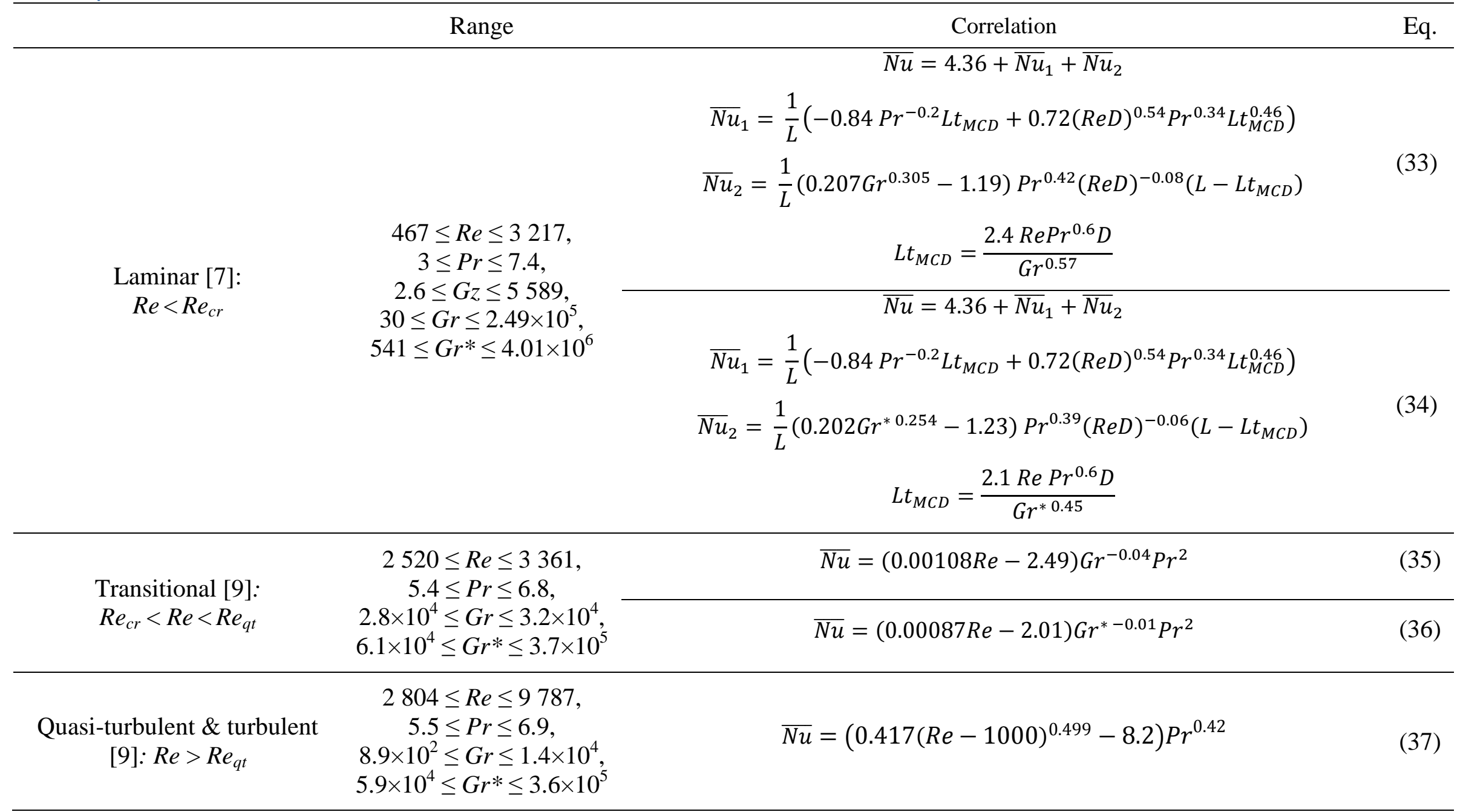


correlations (for different test fluids) can be used in combination with the flow regime maps in this paper.

The performance of the flow regime maps in Fig. 9 and Fig. 10 in the laminar flow regime were determined by comparing $N u / 4.36$ of the experimental data to the $N u / N u_{F C}$ values in the flow regime maps, and the results are summarised in Table 5. From this table it follows that both flow regime maps were able to predict approximately all the experimental data of this study, as well as from literature [21, 22], within $10 \%$. It should therefore be possible to use these flow regime maps as reliable tools to predict the convection flow regime of fully developed flow in a wide range of tube diameters and Prandtl numbers.

Table 5: Ranges and performance of the flow regime maps in Fig. 9 and Fig. 10.

This study only This study and data from literature $[21,22]$

\begin{tabular}{|c|c|c|c|c|c|c|c|c|}
\hline \multirow[t]{2}{*}{ Range } & \multicolumn{4}{|c|}{$\begin{array}{c}546 \leq \operatorname{Re} \leq 11247 \\
3 \leq \operatorname{Pr} \leq 6.5 \\
26 \leq G r \leq 9.4 \times 10^{4} \\
610 \leq G r^{*} \leq 1.2 \times 10^{6}\end{array}$} & \multicolumn{4}{|c|}{$\begin{array}{c}546 \leq \operatorname{Re} \leq 11247, \\
3 \leq P r \leq 139.4, \\
26 \leq G r \leq 4.2 \times 10^{5}, \\
561 \leq G r^{*} \leq 7 \times 10^{6}\end{array}$} \\
\hline & $n$ & $\begin{array}{c} \pm 10 \% \\
{[\%]}\end{array}$ & $\begin{array}{c} \pm 20 \% \\
{[\%]}\end{array}$ & Ave $\%$ & $n$ & $\begin{array}{c} \pm 10 \% \\
{[\%]}\end{array}$ & $\begin{array}{c} \pm 20 \% \\
{[\%]}\end{array}$ & Ave $\%$ \\
\hline Ra: Fig. 9 & 917 & 97 & 100 & 3.4 & 985 & 95 & 99.7 & 3.6 \\
\hline Ra*: Fig. 10 & 916 & 99 & 100 & 2.8 & 984 & 98 & 100 & 3.0 \\
\hline
\end{tabular}

\subsection{Flow regime map for developing flow}

The flow regime maps in literature were developed for fully developed flow. Therefore, the experimental data of both the Mixed Convection Developing (MCD) and Fully Developed (FD) regions, as defined by Meyer and Everts [7], were plotted as a function of Grashof number, Rayleigh number, Richardson number and Richardson-Prandtl product, in Fig. 11 to develop a flow regime map for developing flow. To ensure that the flow regime map is also applicable to high Prandtl number fluids and larger tube diameters, the experimental data of Strickland [21] and Meyer and Abolarin [22] were included. The laminar data was identified using Eq. (22) [8], while the MCD-data was identified using Eq. (38) [7]:

$$
L t_{M C D}=\frac{2.4 \operatorname{RePr}^{0.6} \mathrm{D}}{G r^{0.57}}
$$

The results were coloured according to $N u / N u_{S L}$, where $N u_{S L}$ was obtained using the correlation of Shah and London [1], which is valid for simultaneously hydrodynamically and thermally developing laminar flow using a constant heat flux boundary condition: 
where

$$
N u_{S L}=N u_{1} * N u_{2}-1
$$

$$
\begin{gathered}
N u_{1}=\left[1+\left(\frac{\pi /\left(115.2 z^{*}\right)}{\left\{1+(\operatorname{Pr} / 0.0207)^{2 / 3}\right\}^{1 / 2}\left\{1+\left(220 z^{*} / \pi\right)^{-10 / 9}\right\}^{3 / 5}}\right)^{5 / 3}\right]^{3 / 10} \\
N u_{2}=5.364\left[1+\left(220 z^{*} / \pi\right)^{-10 / 9}\right]^{3 / 10} \\
z^{*}=\frac{\pi}{4 G z}
\end{gathered}
$$

In general, it was found that the four parameters $(G r, R a, R i$ and $R i P r)$ considered in Fig. 11, were not suitable to estimate the convection flow regime of developing flow. As indicated by the red dotted blocks, the colours in the graphs did not change gradually from dark blue to red as free convection effects increased, and 'blue data' fell in the 'red data' regions. Although the Rayleigh number was suitable for fully developed flow (Fig. 7), another parameter had to be added to $x$-axis to account for developing flow.

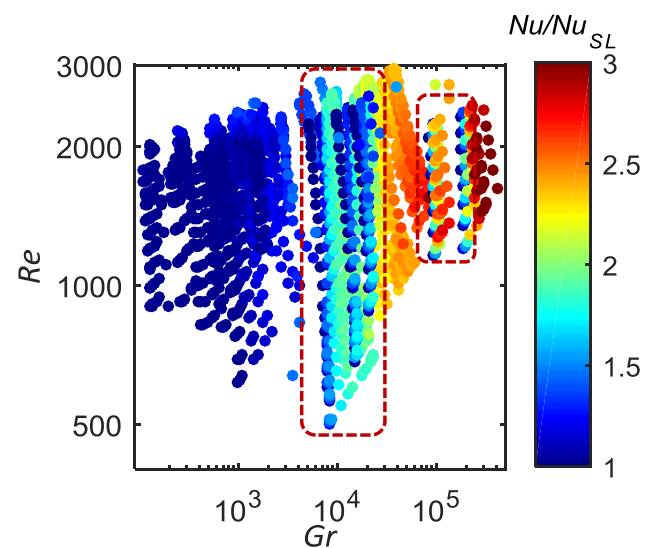

(a)

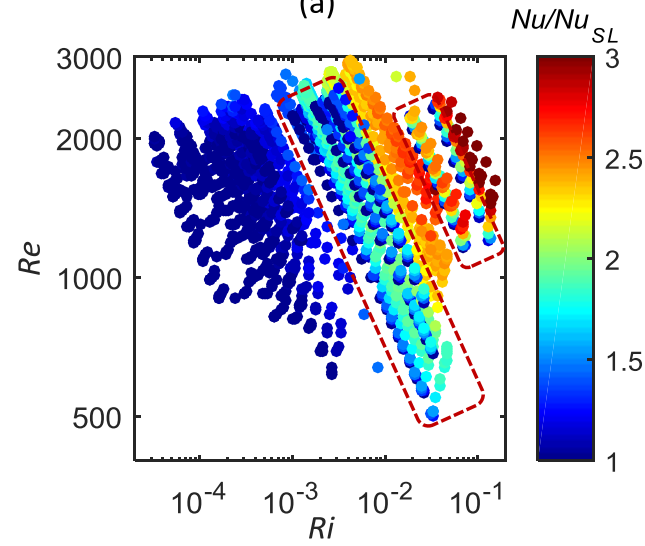

(c)

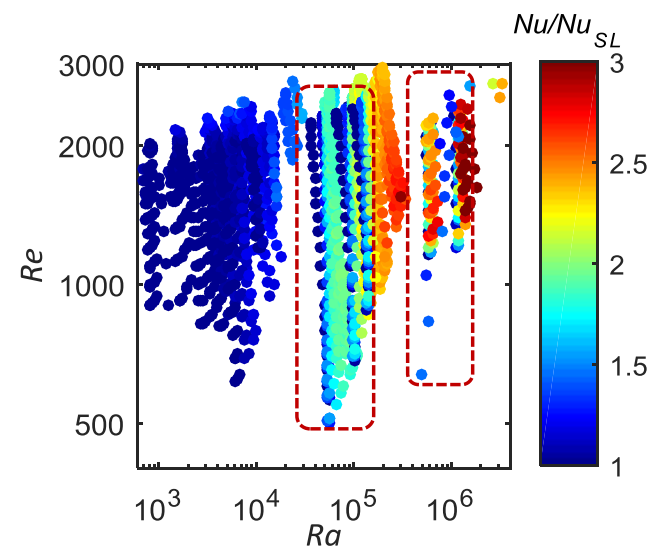

(b)

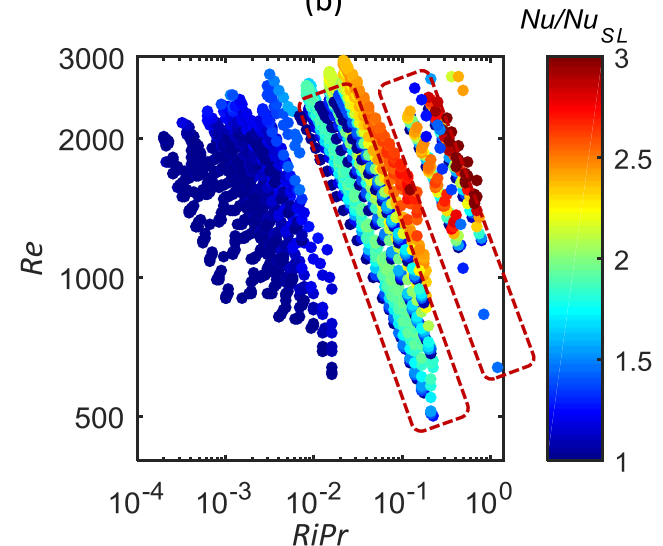

(d)

Fig. 11: MCD and FD experimental data of this study and literature [21, 22], plotted as a function of (a) $G r$, (b) $R a$, (c) $R i$ and (d) RiPr. The data is coloured according to $\mathrm{Nu} / \mathrm{Nu} u_{S L}$.

The Grashof number, Rayleigh number, Richardson number and Richardson-Prandtl product in Fig. 11 were multiplied by $x / D$ in Fig. 12 to account for developing flow. From 
this figure it follows that parameter $\operatorname{Ri}(x / D)$ (Fig. 12(c)) was able to produce the best, relatively smooth, contour that changed from dark blue to red as free convection effects increased, for both water and ethylene glycol data. The red dotted blocks indicate the data that fell into the incorrect regions.

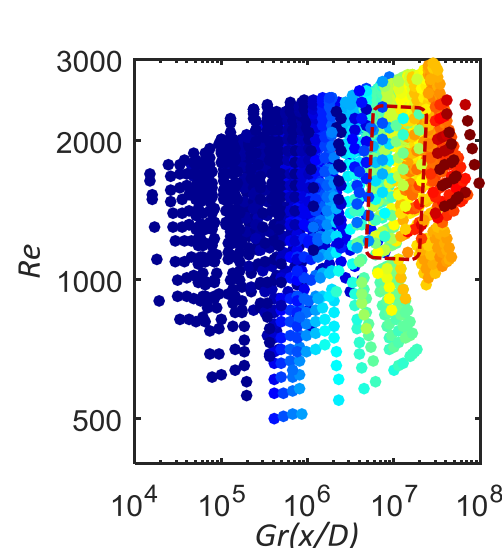

(a)

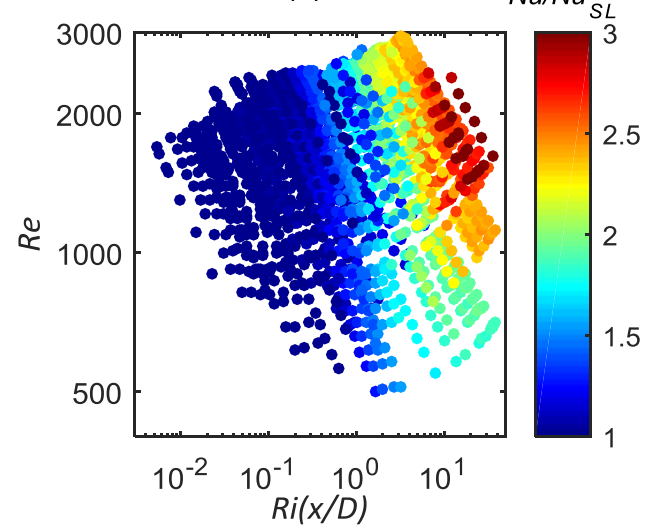

(c)

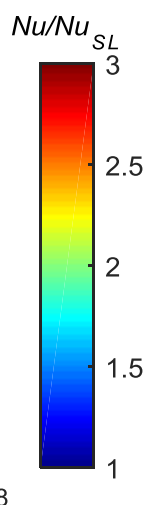

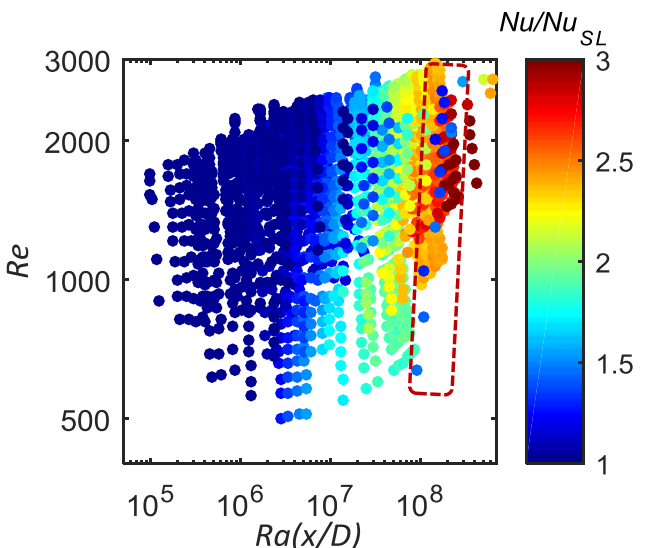

(b)

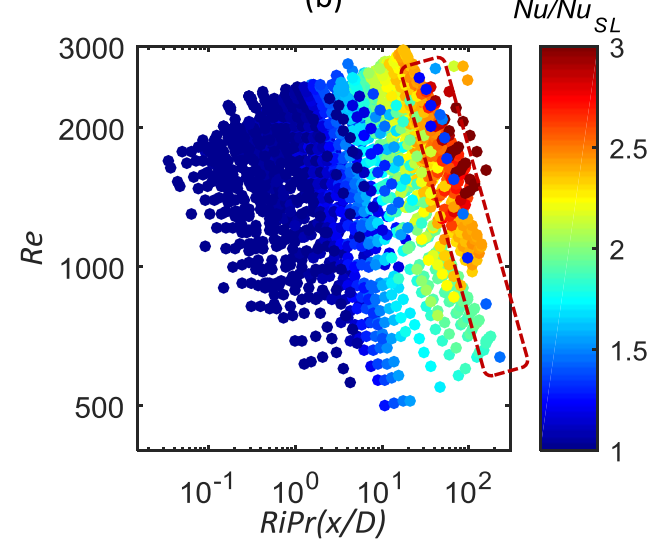

(d)

Fig. 12: MCD and FD experimental data of this study and literature [21, 22], plotted as a function of (a) Gr(x/D), (b) $\operatorname{Ra}(\mathrm{x} / \mathrm{D}),(\mathrm{c}) \operatorname{Ri}(\mathrm{x} / \mathrm{D})$ and $(\mathrm{d}) \operatorname{RiPr}(\mathrm{x} / \mathrm{D})$. The data is coloured according to $\mathrm{Nu} / \mathrm{Nu} u_{S L}$.

The Graetz number can also be used to account for axial position when the flow is still developing. Therefore, the Grashof number, Rayleigh number, Richardson number and Richardson-Prandtl product in Fig. 11 were divided by the Graetz number and the results are compared in Fig. 13. Although all parameters might give reasonable results, best results were obtained using the parameters $R a / G z$ (Fig. 13(b)) and RiPr/Gz (Fig. 13(d)). Approximately smooth contours that changed from dark blue to red as the free convection effects increased, were obtained for both water and ethylene glycol data. It was decided to use $R a / G z$ on the $x$ axis of the flow regime maps for developing flow, since free convection effects increased approximately horizontally (indicated by the black arrows) for $R a / G z$ (Fig. 13(b)), while it increased diagonally for $\mathrm{RiPr} / \mathrm{Gz}$ (Fig. 13(d)). The red dotted blocks indicate the data that fell into the incorrect regions. 

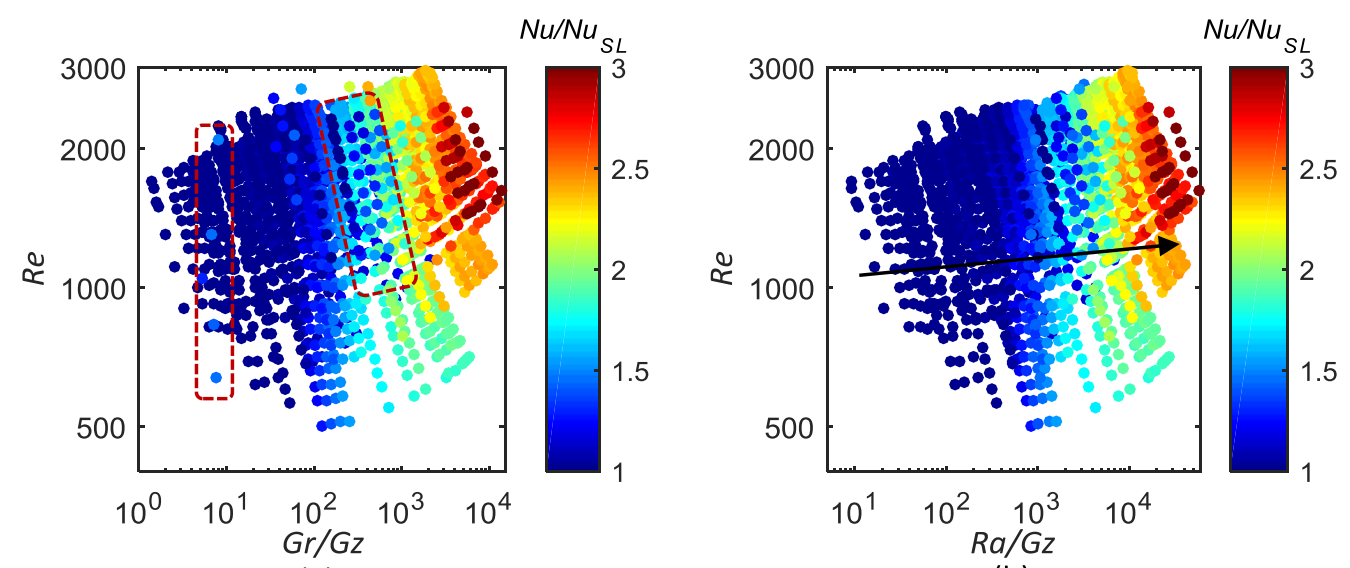

(a)
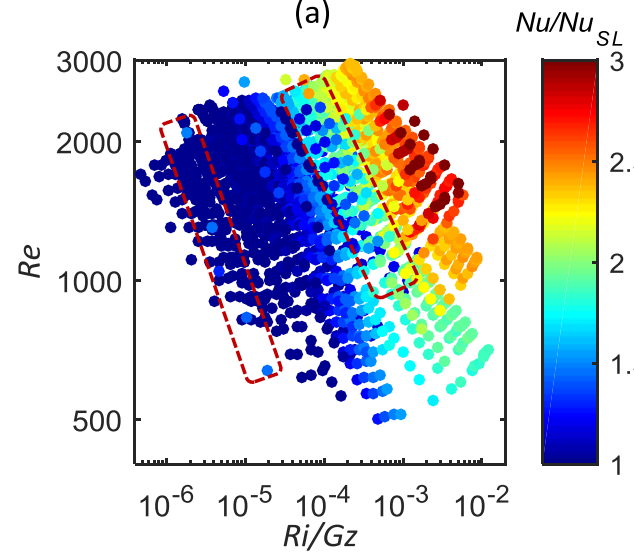

(c)

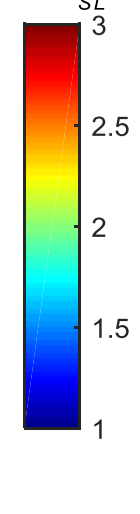

(b)

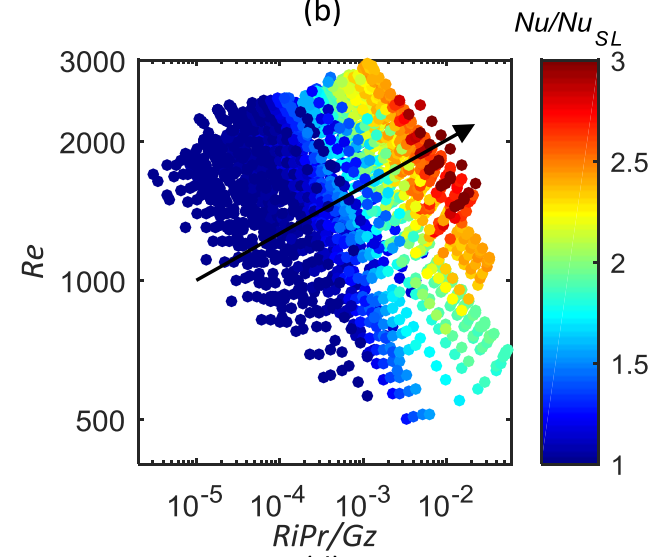

(d)

Fig. 13: $M C D$ and FD experimental data of this study and literature [21, 22], plotted as a function of (a) $G r / G z,(b) R a / G z$, (c) $R i / G z$ and (d) RiPr/Gz. The data is coloured according to $\mathrm{Nu} / \mathrm{Nu} u_{S L}$.

From Fig. 12 and Fig. 13 it was concluded that both $R i(x / D)$ (Fig. 12(c)) and $R a / G z$ (Fig. 13(b)) were suitable parameters to be used for the flow regime map. The same procedure as in Fig. 8 was followed to obtain the flow regime maps in terms of $\operatorname{Ri}(x / D)$ (Fig. 14) and $R a / G z$ (Fig. 15). In both flow regime maps, $N u_{F C}=N u_{S L}$ for all data below the $R e_{c r}$-lines (Eqs. (40) and (44)), while $N u_{F C}$ is the corresponding forced convection Nusselt number from general literature for all data above the $R e_{q t}$-lines (Eqs. (41) and (45)). It should be noted that the values of $N u_{F C}$ given in the rest of the paper is not only a function of Reynolds and Prandtl, but very important a function of axial position, as the flow is developing. In the transitional flow regime $\left(R e_{c r}<R e<R e_{q t}\right), N u / N u_{F C}$ only gives an estimate of whether free convection effects can be expected or not, and not the actual Nusselt number values. From these figures it follows that $R i(x / D)<0.21$ and $R a / G z<518$ (indicated by the dotted yellow lines), can be used as Reynolds number independent criteria $\left(N u / N u_{F C}=1.1\right)$ that will ensure that the flow will most probably be forced convection. More conservative criteria $\left(N u / N u_{F C}=1\right)$ will be $R i(x / D)<0.14$ and $R a / G z<318$. 


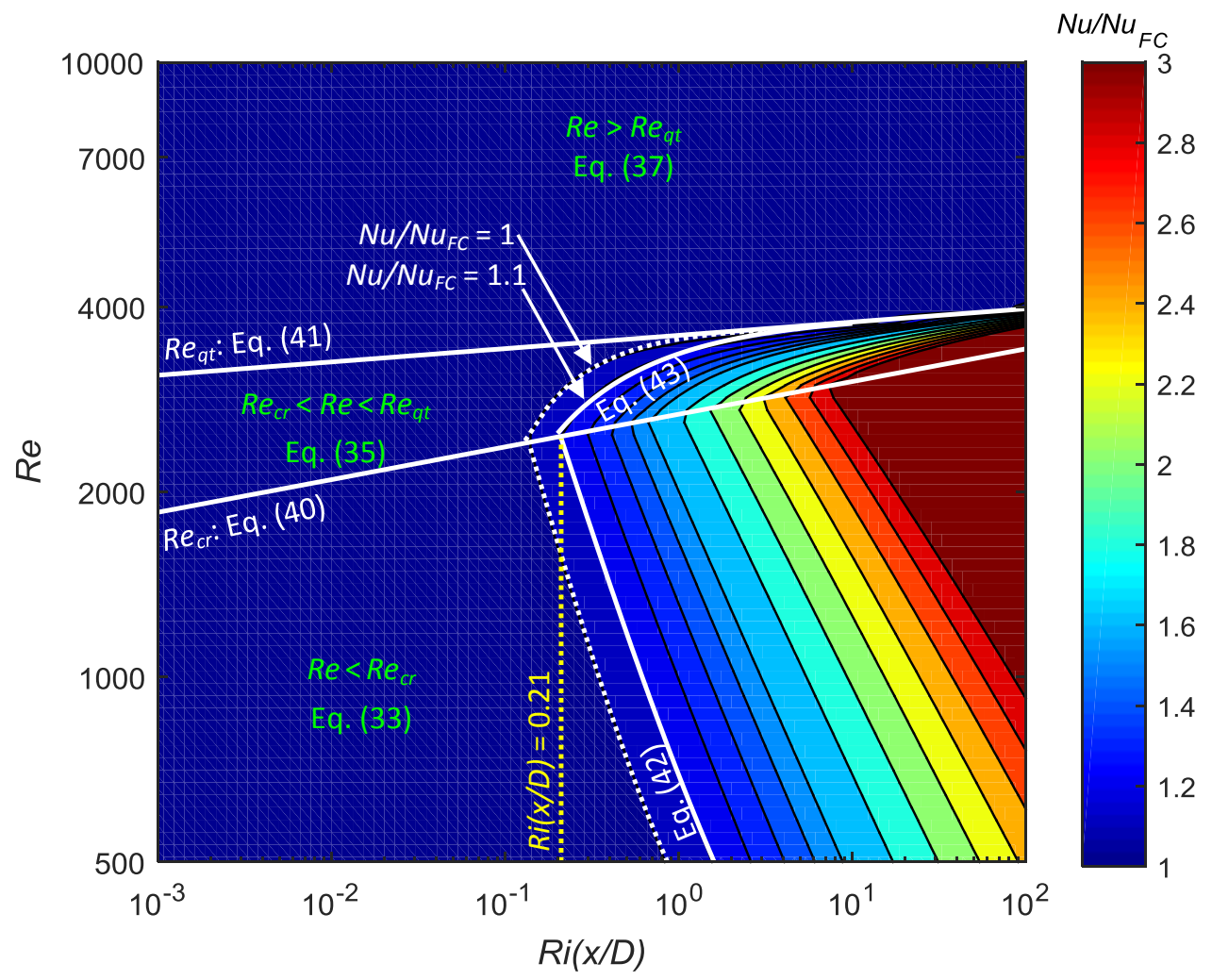

Fig. 14: Flow regime map for developing and fully developed flow as a function of $R e$ and $R i(x / D)$. $N u_{F C}=N u_{S L}$ for all data below Eq. (40), while $N u_{F C}$ is the corresponding forced convection Nusselt number from general literature for all data above Eq. (41). In the transitional flow regime $\left(R e_{c r}<R e<R e_{q t}\right), N u / N u_{F C}$ only gives an estimate of whether free convection effects can be expected or not, and not the actual Nusselt number values.

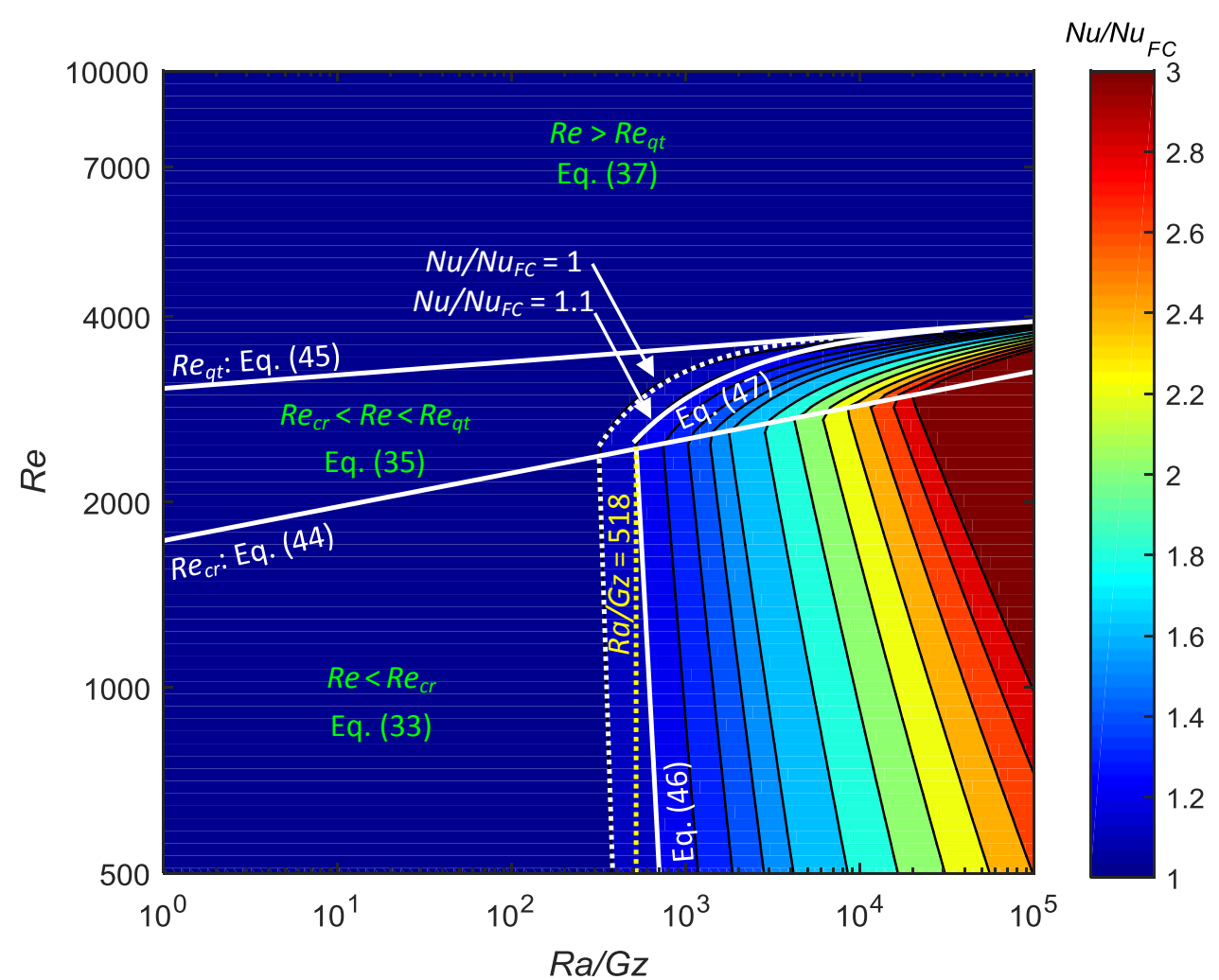

Fig. 15: Flow regime map for developing and fully developed flow as a function of $R e$ and $R a / G z . N u_{F C}=N u_{S L}$ for all data below Eq. (44), while $N u_{F C}$ is the corresponding forced convection Nusselt number from general literature for all data above Eq. (45). In the transitional flow regime $\left(R e_{c r}<R e<R e_{q t}\right), N u / N u_{F C}$ only gives an estimate of whether free convection effects can be expected or not, and not the actual Nusselt number values. 
The equations of the transitional flow regime boundaries and the forced/mixed convection boundaries are summarised in Table 6, while the performance of the flow regime maps is summarised in Table 8.

Table 6: Equations of the transitional flow regime boundaries and forced/mixed convection boundaries, and ranges of the flow regime maps as a function of $\operatorname{Ri}(x / D)$ and $R a / G z$.

\begin{tabular}{|c|c|c|c|}
\hline & & Correlation & Eq. \\
\hline \multirow{4}{*}{$\begin{array}{c}\operatorname{Ri}(x / D) \\
(\text { Fig. 14) }\end{array}$} & $R e_{c r}$ & $R e_{c r}=2675.3(\operatorname{Ri}(x / D))^{0.0532}$ & $(40)$ \\
\hline & $R e_{q t}$ & $R e_{q t}=3595.1(\operatorname{Ri}(x / D))^{0.0216}$ & $(41)$ \\
\hline & $\operatorname{Re}<\operatorname{Re} e_{c r}$ & $F C / M C=546.3(R i(x / D))^{-0.9212}+145.7$ & $(42)$ \\
\hline & $\operatorname{Re}_{c r}<\operatorname{Re}<R e_{q t}$ & $F C / M C=-540.8(R i(x / D))^{-0.5939}+3896$ & $(43)$ \\
\hline \multirow{4}{*}{$\begin{array}{c}R a / G z \\
\text { (Fig. 15) }\end{array}$} & $R e_{c r}$ & $R e_{c r}=1730.9(R a / G z)^{0.0549}$ & (44) \\
\hline & $R e_{q t}$ & $R e_{q t}=3056.4(R a / G z)^{0.0217}$ & $(45)$ \\
\hline & $\operatorname{Re}<\operatorname{Re}_{c r}$ & $F C / M C=6.591 \times 10^{16}(R a / G z)^{-4.944}-50.47$ & $(46)$ \\
\hline & $\operatorname{Re}_{c r}<\operatorname{Re}<\operatorname{Re}_{q t}$ & $F C / M C=-3.582 \times 10^{4}(R a / G z)^{-0.512}+3984$ & $(47)$ \\
\hline & Ranges & $\begin{aligned} 502 & \leq R e \leq 11247 \\
3 & \leq P r \leq 139.4 \\
2.7 & \leq G z \leq 5.5 \times 10^{3} \\
26 & \leq G r \leq 4.2 \times 10^{5} \\
561 & \leq G r^{*} \leq 7 \times 10^{6}\end{aligned}$ & \\
\hline
\end{tabular}

The same procedure was used to obtain flow regime maps in terms of the modified Grashof, Rayleigh and Richardson numbers, since the temperature difference (required to calculate the Grashof number for constant heat flux problems) is not always available (except when the heat transfer coefficients are known), while the heat flux usually is. Fig. 16 and Fig. 17 contain the flow regime maps in terms of $\operatorname{Ri}(x / D)$ and $R a / G z$, respectively. In both flow regime maps, $N u_{F C}=N u_{S L}$ for all data below the $R e_{c r}$-line (Eqs. (48) and (52)), while $N u_{F C}$ is the corresponding forced convection Nusselt number from general literature for all data above the $R e_{q t}$-line (Eqs. (49) and (53)). In the transitional flow regime $\left(R e_{c r}<R e<R e_{q t}\right), N u / N u_{F C}$ only gives an estimate of whether free convection effects can be expected or not, and not the actual Nusselt number values.

From these figures it follows that $R i^{*}(x / D)<1.64$ and $R a * / G z<4038$ (indicated by the dotted yellow lines), can be used as Reynolds number independent criteria $\left(N u / N u_{F C}=1.1\right)$ that will ensure that the flow regime will most probably be forced convection. More conservative criteria $\left(N u / N u_{F C}=1\right)$ will be $R i *(x / D)<1$ and $R a * / G z<2364$. Table 7 summarises the equations of the transitional flow regime boundaries and forced/mixed convection boundaries, and the performance of these flow regime maps is summarised in Table 8. 


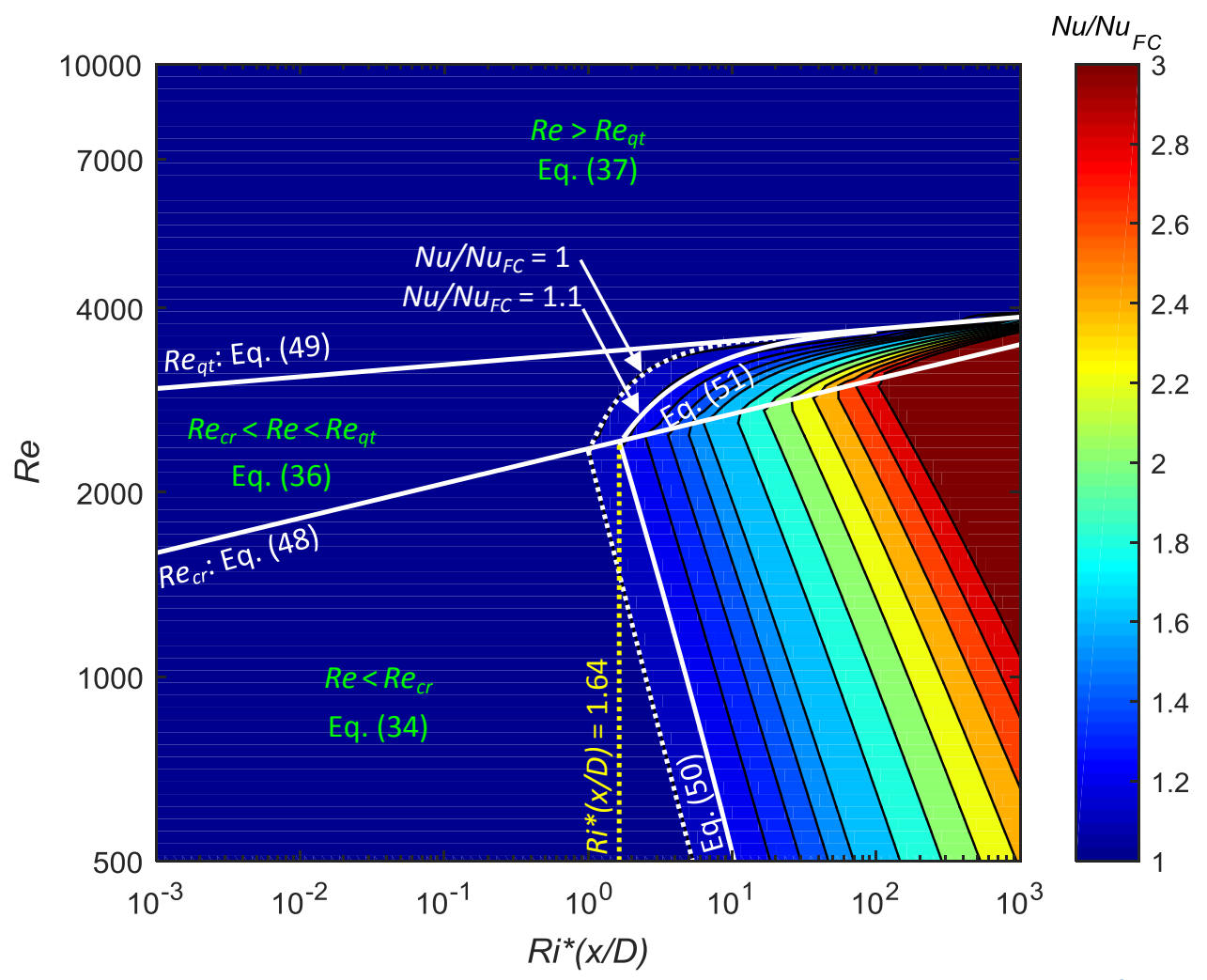

Fig. 16: Flow regime map for developing and fully developed flow as a function of $\operatorname{Re}$ and $R i^{*}(x / D)$. $N u_{F C}=N u_{S L}$ for all data below Eq. (48), while $N u_{F C}$ is the corresponding forced convection Nusselt number from general literature for all data above Eq. (49). In the transitional flow regime $\left(R e_{c r}<R e<R e_{q t}\right), N u / N u_{F C}$ only gives an indication of whether free convection effects can be expected or not, and not the actual Nusselt number values.

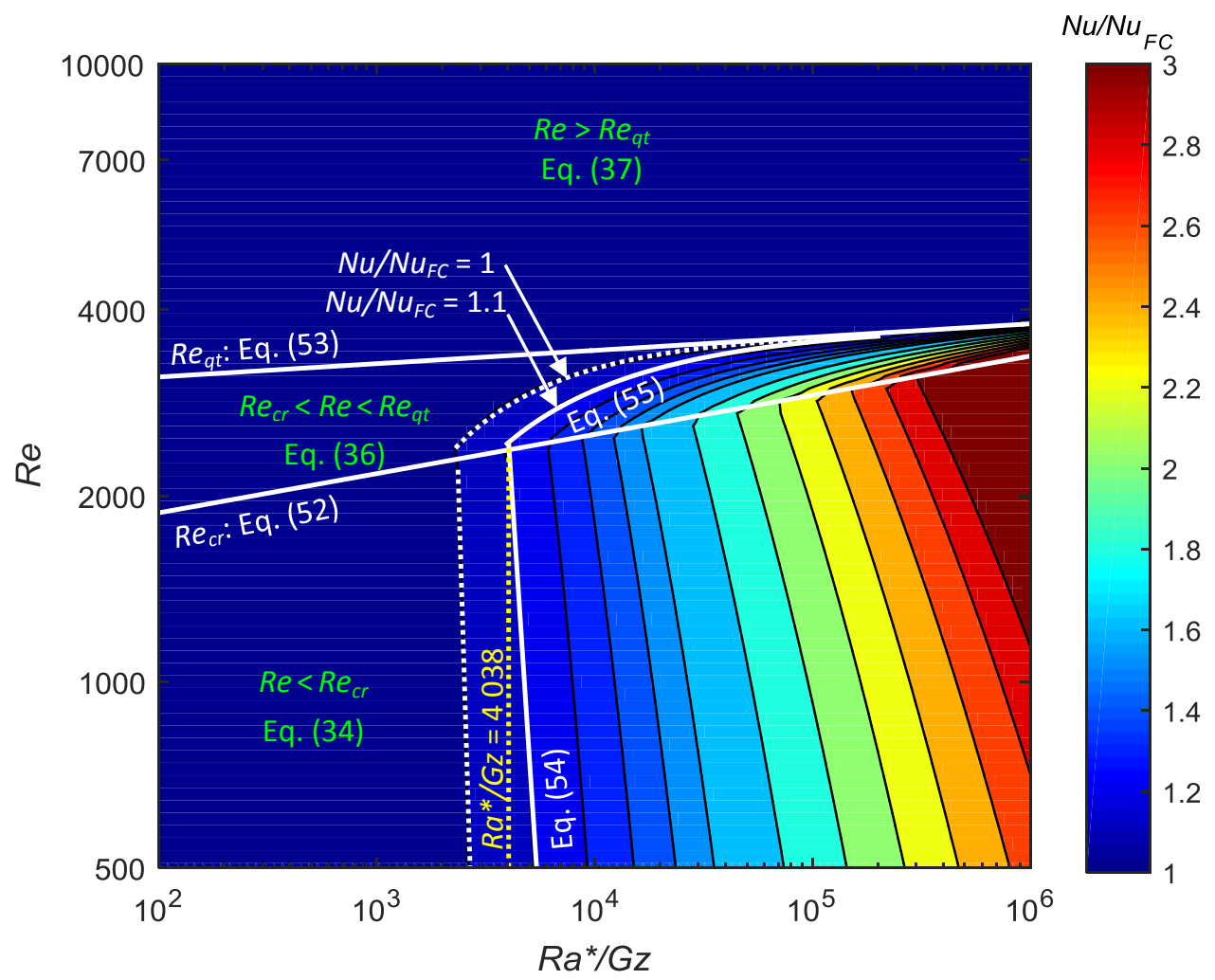

Fig. 17: Flow regime map for developing and fully developed flow as a function of $R e$ and $R a^{*} / G z . N u_{F C}=N u_{S L}$ for all data below Eq. (52), while $N u_{F C}$ is the corresponding forced convection Nusselt number from general literature for all data above Eq. (53). In the transitional flow regime $\left(R e_{c r}<R e<R e_{q t}\right), N u / N u_{F C}$ only gives an indication of whether free convection effects can be expected or not, and not the actual Nusselt number values. 
Table 7: Equations of the transitional flow regime boundaries and forced/mixed convection boundaries, and ranges of flow regime maps as a function of $R i^{*}(x / D)$ and $R a^{*} / G z$.

\begin{tabular}{|c|c|c|c|}
\hline & & Correlation & Eq. \\
\hline \multirow{4}{*}{$\begin{array}{l}R i^{*}(x / D) \\
\text { (Fig. 16) }\end{array}$} & $R e_{c r}$ & $R e_{c r}=2355.5\left(R i^{*}(x / D)\right)^{0.0567}$ & $(48)$ \\
\hline & $R e_{q t}$ & $R e_{q t}=3377.3\left(R i^{*}(x / D)\right)^{0.0195}$ & $(49)$ \\
\hline & $R e<\operatorname{Re}_{c r}$ & $F C / M C=3724\left(R i^{*}(x / D)\right)^{-0.7711}+115.4$ & $(50)$ \\
\hline & $R e_{c r}<R e<R e_{q t}$ & $F C / M C=-1868\left(R i^{*}(x / D)\right)^{-0.6159}+3772$ & $(51)$ \\
\hline \multirow{5}{*}{$\begin{array}{c}R a * / G z \\
\text { (Fig. 17) }\end{array}$} & $R e_{c r}$ & $R e_{c r}=1401.3\left(R a^{*} / G z\right)^{0.0635}$ & $(52)$ \\
\hline & $\operatorname{Re}_{q t}$ & $R e_{q t}=2820.8\left(R a^{*} / G z\right)^{0.0215}$ & $(53)$ \\
\hline & $\operatorname{Re}<\operatorname{Re}_{c r}$ & $F C / M C=5.8 \times 10^{22}\left(R a^{*} / G z\right)^{-5.373}$ & $(54)$ \\
\hline & $\operatorname{Re}_{c r}<\operatorname{Re}<\operatorname{Re}_{q t}$ & $F C / M C=-1.224 \times 10^{4}\left(R a^{*} / G z\right)^{-0.543}+3787$ & $(55)$ \\
\hline & Ranges & $\begin{aligned} 502 & \leq R e \leq 11247 \\
3 & \leq P r \leq 139.4 \\
2.7 & \leq G z \leq 5.5 \times 10^{3} \\
26 & \leq G r \leq 4.2 \times 10^{5} \\
561 & \leq G r^{*} \leq 7 \times 10^{6}\end{aligned}$ & \\
\hline
\end{tabular}

The performance was determined by comparing $N u / N u_{S L}$ of the experimental data and the $N u / N u_{F C}$ values in the flow regime maps in Fig. 14 to Fig. 17. From Table 8 it follows that all four flow regime maps were able to predict approximately $80 \%$ of the data within $10 \%$, and almost all the data within 20\%. The two flow regime maps (Fig. 16 and Fig. 17) that were a function of heat flux $\left(G r^{*}\right)$ performed slightly better than the flow regime maps (Fig. 14 and Fig. 15) that were a function of temperature difference $(\mathrm{Gr})$. It can be concluded that these four flow regime maps can be used as reliable tools to predict the convection flow regime for developing and fully developed flow in a wide range of tube diameters and Prandtl numbers.

Table 8: Ranges and performance of the flow regime maps in Fig. 14 to Fig. 17 using developing and fully developed data.

\begin{tabular}{|c|c|c|c|c|c|c|c|c|}
\hline \multirow{3}{*}{ Range } & \multicolumn{4}{|c|}{ This study only } & \multicolumn{4}{|c|}{$\begin{array}{c}\text { This study and data from } \\
\text { literature }[21,22]\end{array}$} \\
\hline & \multicolumn{4}{|c|}{$\begin{array}{c}502 \leq R e \leq 2936, \\
3 \leq P r \leq 6.9 \\
2.7 \leq G z \leq 689 \\
106 \leq G r \leq 9.39 \times 10^{4}, \\
569 \leq G r^{*} \leq 1.21 \times 10^{6}\end{array}$} & \multicolumn{4}{|c|}{$\begin{array}{c}502 \leq R e \leq 2936, \\
3 \leq P r \leq 139.5, \\
2.7 \leq G z \leq 1241 \\
106 \leq G r \leq 4.19 \times 10^{5} \\
569 \leq G r^{*} \leq 7.03 \times 10^{6}\end{array}$} \\
\hline & $n$ & $\begin{array}{c} \pm 10 \% \\
{[\%]}\end{array}$ & $\begin{array}{c} \pm 20 \% \\
{[\%]}\end{array}$ & Ave $\%$ & $n$ & $\begin{array}{c} \pm 10 \% \\
{[\%]}\end{array}$ & $\begin{array}{c} \pm 20 \% \\
{[\%]}\end{array}$ & Ave $\%$ \\
\hline Ri(x/D): Fig. 14 & 1776 & 77 & 97 & 6.7 & 2174 & 79 & 95 & 6.6 \\
\hline Ra/Gz: Fig. 15 & 1776 & 78 & 97 & 6.7 & 2152 & 80 & 95 & 6.6 \\
\hline$R i *(x / D):$ Fig. 16 & 1777 & 82 & 99 & 5.7 & 2159 & 84 & 96 & 5.9 \\
\hline$R a * / G z:$ Fig. 17 & 1747 & 83 & 99 & 5.7 & 2085 & 84 & 96 & 5.9 \\
\hline
\end{tabular}


To determine the validity/accuracy of the flow regime maps for Prandtl numbers less than one, the performance of the flow regime maps was determined using experimental data conducted using air as the test fluid. Apart from the experimental data of McComas and Eckert [28], it was found that limited complete experimental data (Reynolds numbers, Nusselt numbers, Grashof numbers and axial position) conducted using air were available in literature. The performance of the flow regime maps was determined using 70 experimental data points $(220<\operatorname{Re}<743, \operatorname{Pr} \approx 0.7,0.13<G r<1000)$, and the flow regime maps were able to predict $86 \%$ of the data within $10 \%$ and all the data within $20 \%$.

The flow regime maps in Fig. 14 to Fig. 17 were generated using developing flow and fully developed flow data. The validity/accuracy of these flow regime maps in the laminar flow regime using fully developed data only, were determined by comparing $N u / N u_{S L}$ of the experimental data and the $N u / N u_{F C}$ values in the four flow regime maps, and the results are summarised in Table 9. As all four flow regime maps were able to predict almost all the data within $20 \%$, it is confirmed that these flow regime maps are valid for both developing and fully developed flow.

Table 9: Performance of the flow regime maps in Fig. 14 to Fig. 17 using fully developed data only.

\begin{tabular}{|c|c|c|c|c|c|c|c|c|}
\hline 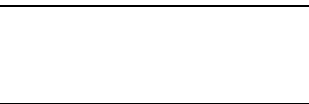 & \multicolumn{4}{|c|}{ This study only } & \multicolumn{4}{|c|}{$\begin{array}{c}\text { This study and data from } \\
\text { literature }[21,22]\end{array}$} \\
\hline \multirow[t]{2}{*}{ Range } & \multicolumn{4}{|c|}{$\begin{array}{c}546 \leq \operatorname{Re} \leq 2936, \\
3 \leq \operatorname{Pr} \leq 6.5, \\
2.7 \leq G z \leq 45, \\
137 \leq G r \leq 9.39 \times 10^{4}, \\
610 \leq G r^{*} \leq 1.21 \times 10^{6}\end{array}$} & \multicolumn{4}{|c|}{$\begin{array}{c}546 \leq R e \leq 2936 \\
3 \leq \operatorname{Pr} \leq 139.5 \\
2.7 \leq G z \leq 1241 \\
137 \leq G r \leq 4.19 \times 10^{5} \\
610 \leq G r^{*} \leq 7.03 \times 10^{6}\end{array}$} \\
\hline & $n$ & $\begin{array}{c} \pm 10 \% \\
{[\%]}\end{array}$ & $\begin{array}{c} \pm 20 \% \\
{[\%]}\end{array}$ & Ave $\%$ & $n$ & $\begin{array}{c} \pm 10 \% \\
{[\%]}\end{array}$ & $\begin{array}{c} \pm 20 \% \\
{[\%]}\end{array}$ & Ave $\%$ \\
\hline $\operatorname{Ri}(x / D)$ : Fig. 14 & 917 & 73 & 95 & 7.1 & 985 & 72 & 94 & 7.4 \\
\hline$R a / G z:$ Fig. 15 & 917 & 74 & 95 & 7.1 & 985 & 72 & 94 & 7.3 \\
\hline$R i *(x / D):$ Fig. 16 & 917 & 85 & 99 & 5.3 & 985 & 83 & 98 & 5.7 \\
\hline$R a * / G z:$ Fig. 17 & 917 & 85 & 99 & 5.3 & 985 & 84 & 98 & 5.6 \\
\hline
\end{tabular}

\section{Conclusions}

A flow regime map is a valuable tool that can be used to determine whether free convection effects can be neglected (forced convection dominates) or whether it is significant (mixed convection dominates), for a given boundary condition and values of $\operatorname{Re}, \operatorname{Pr}, \mathrm{Gr}$ and $x / D$. It has been found that although the existing constant heat flux boundary condition flow regime maps were accurate for high Prandtl number fluids, it became inaccurate once the 
Prandtl number and tube diameter was decreased, for example when water is used in small diameter tubes.

The purpose of this paper was thus to evaluate the existing flow regime maps using the experimental data of this study which was obtained using water as the test fluid in test sections with inner diameters of $4 \mathrm{~mm}$ and $11.5 \mathrm{~mm}$, as well as to develop new flow regime maps that can be used for both high and low Prandtl number fluids in a wide range of tube diameters. A total of six flow regime maps were developed and these flow regime maps are unique for four reasons. Firstly, it contains contour lines that show the Nusselt number enhancements due to the free convection effects. Secondly, it is valid for a wide range of tube diameters and Prandtl numbers. Thirdly, the flow regime maps were developed as a function of temperature difference (Grashof number) and heat flux (modified Grashof number). Finally, four of the six flow regime maps were not only valid for fully developed flow, but also developing flow. Two flow regime maps were developed for fully developed flow in terms of $R a$, and $R a^{*}$ and were able to predict almost all the data within $10 \%$. Four flow regime maps that were valid for developing and fully developed flow were developed in terms of $R i(x / D), R a / G z, R i^{*}(x / D)$ and $R a * / G z$, respectively. All four flow regime maps were able to predict approximately $80 \%$ of the data within $10 \%$ and almost all the data within $20 \%$. It can be concluded that these flow regime maps can be used as reliable tools to predict the convection flow regime for developing and fully developed flow for a wide range of tube diameters and Prandtl numbers.

\section{Acknowledgements}

The funding obtained in South Africa from the NRF, Stellenbosch University/ University of Pretoria Solar Hub, CSIR, EEDSM Hub, RDP and NAC is acknowledged and duly appreciated. The authors would also like to thank Professor A.J. Ghajar from Oklahoma State University, for making the experimental data of Strickland [21] available. This work was produced as part of a $\mathrm{PhD}$ in the Department of Mechanical Engineering at the University of Pretoria by the first author, under the supervision of the second author.

\section{References}

[1] R.K. Shah, A.L. London, Laminar Flow Forced Convection in Ducts, Academic Press, New York, 1978.

[2] B. Metais, E. Eckert, Forced, mixed, and free convection regimes, Journal of Heat Transfer, 86(2) (1964) 295-296.

[3] A.J. Ghajar, L.M. Tam, Flow regime map for a horizontal pipe with uniform wall heat flux and three inlet configurations, Exp. Therm. Fluid Sci., 10(3) (1995) 287-297. 
[4] L.M. Tam, A.J. Ghajar, H.K. Tam, S.C. Tam, Development of a flow regime map for a horizontal pipe with the multi-classification Support Vector Machines, in: 2008 Proceedings of the ASME Summer Heat Transfer Conference, HT 2008, 2009, pp. 537-547.

[5] H.K. Tam, L.M. Tam, A.J. Ghajar, C.W. Cheong, Development of a unified flow regime map for a horizontal pipe with the support vector machines, in: AIP Conference Proceedings, 2010, pp. 608-613.

[6] A.J. Ghajar, L.M. Tam, Heat transfer measurements and correlations in the transition region for a circular tube with three different inlet configurations, Exp. Therm. Fluid Sci., 8(1) (1994) 79-90.

[7] J.P. Meyer, M. Everts, Single-phase mixed convection of developing and fully developed flow in smooth horizontal circular tubes in the laminar and transitional flow regimes, Int. J. Heat Mass Transf., (2017), Manuscript nr: HMT_2017_2231, submitted on 7 June 2017.

[8] M. Everts, J.P. Meyer, Heat transfer of developing and fully developed flow in smooth horizontal tubes in the transitional flow regime, Int. J. Heat Mass Transf., (2017), Manuscript nr: HMT_2017_2232, submitted on 7 June 2017.

[9] M. Everts, J.P. Meyer, Relationship between pressure drop and heat transfer of developing and fully developed flow in smooth horizontal circular tubes in the laminar, transitional, quasi-turbulent and turbulent flow regimes, Int. J. Heat Mass Transf., (2017), Manuscript nr: HMT_2017_2233, submitted on 7 June 2017.

[10] M. Everts, Single-phase mixed convection of developing and fully developed flow in smooth horizontal circular tubes in the laminar, transitional, quasi-turbulent and turbulent flow regimes, $\mathrm{PhD}$ thesis, University of Pretoria, Pretoria, 2017 (under examination).

[11] A.J. Ghajar, L.M. Tam, Laminar-transition-turbulent forced and mixed convective heat transfer correlations for pipe flows with different inlet configurations, in: Winter Annual Meeting of the American Society of Mechanical Engineers, Publ by ASME, New York, United States, 1991, pp. 15-23.

[12] A.J. Ghajar, K.F. Madon, Pressure drop measurements in the transition region for a circular tube with three different inlet configurations, Exp. Therm. Fluid Sci., 5(1) (1992) 129-135.

[13] A.J. Ghajar, C.C. Tang, W.L. Cook, Experimental investigation of friction factor in the transition region for water flow in minitubes and microtubes, Heat Transfer Eng, 31(8) (2010) 646-657.

[14] L.M. Tam, A.J. Ghajar, Effect of Inlet Geometry and Heating on the Fully Developed Friction Factor in the Transition Region of a Horizontal Tube, Exp. Therm. Fluid Sci., 15(1) (1997) 52-64.

[15] L.M. Tam, A.J. Ghajar, The unusual behavior of local heat transfer coefficient in a circular tube with a bell-mouth inlet, Exp. Therm. Fluid Sci., 16(3) (1998) 187-194.

[16] H.K. Tam, L.M. Tam, A.J. Ghajar, S.C. Tam, T. Zhang, Experimental investigation of heat transfer, friction factor, and optimal fin geometries for the internally microfin tubes in the transition and turbulent regions, J. Enhanced Heat Transf., 19(5) (2012) 457-476.

[17] H.K. Tam, L.M. Tam, A.J. Ghajar, Effect of inlet geometries and heating on the entrance and fully-developed friction factors in the laminar and transition regions of a horizontal tube, Exp. Therm. Fluid Sci., 44 (2013) 680-696.

[18] J.A. Olivier, J.P. Meyer, Single-phase heat transfer and pressure drop of the cooling of water inside smooth tubes for transitional flow with different inlet geometries (RP-1280), HVAC R Res, 16(4) (2010) 471-496.

[19] G. Maranzana, I. Perry, D. Maillet, Mini- and micro-channels: influence of axial conduction in the walls, Int. J. Heat Mass Transf., 47(17) (2004) 3993-4004.

[20] A. Bakker, R.D. LaRoche, E.M. Marshall, Laminar flow in static mixers with helical elements, in: The Online CFM Book, 2000. 
[21] D.T. Strickland, Heat transfer measurements in the transition region for a horizontal circular tube with a square-edged entrance, Masters dissertation, Oklahoma State University, Stillwater, 1990.

[22] J.P. Meyer, S.M. Abolarin, Heat transfer and pressure drop in the transitional flow regime for a smooth circular tube with twisted tape inserts and a square-edge inlet, Int. J. Heat Mass Transf., 117 (2018) 11-29.

[23] C.O. Popiel, J. Wojtkowiak, Simple formulas for thermophysical properties of liquid water for heat transfer calculations [from $\mathrm{O}^{\circ} \mathrm{C}$ to $150^{\circ} \mathrm{C}$ ], Heat Transfer Eng, 19(3) (1998) 87-101.

[24] P.F. Dunn, Measurement and Data Analysis for Engineering and Science, 2nd ed., CRC Press, United States of America, 2010.

[25] S.M. Morcos, A.E. Bergles, Experimental investigation of combined forced and free laminar convection in horizontal tubes, Journal of Heat Transfer, 97(2) (1975) 212-219.

[26] V. Gnielinski, New equations for heat and mass-transfer in turbulent pipe and channel flow, International Chemical Engineering, 16(2) (1976) 359-368.

[27] Y.A. Cengel, A.J. Ghajar, Heat and Mass Transfer: Fundamentals and Applications, 5th ed., McGraw-Hill, 2015.

[28] S. McComas, E. Eckert, Combined free and forced convection in a horizontal circular tube, Journal of Heat Transfer, 88(2) (1966) 147-152. 